\title{
Seismic collapse prevention system for steel-frame buildings
}

\author{
Johnn P. Judd ${ }^{1 *}$, Finley A. Charney ${ }^{2}$ \\ ${ }^{1}$ Dept. of Civil \& Arch. Eng., Univ. of Wyoming, 1000 E. Univ. Ave., Laramie WY 82071 USA. \\ ${ }^{2}$ Dept. of Civil \& Environ. Eng., Virginia Tech, 200 Patton Hall, Blacksburg, VA 24060 USA.
}

\begin{abstract}
This paper presents an innovative "collapse prevention" system for seismic resistant design in new construction and existing buildings. The collapse prevention system consists of a collapse inhibiting mechanism, such as a pair of slack cables or loose linkages, working in tandem with the main lateral-force resisting system and engaging the gravity framing to avert collapse. In this holistic design approach, the main lateral-force resisting system and gravity framing are used to provide adequate performance under low to moderate level ground motions, and the collapse inhibiting mechanism is deployed as a back-up to provide life safety under extreme ground motions. The collapse inhibiting mechanism may be augmented with energy dissipation devices (small viscous fluid or visco-elastic solid dampers) to enhance performance under wind or small seismic events. Analytical performance of archetypical 1-story, 2-story, 4-story, and 8-story steel-frame buildings employing collapse prevention systems indicate that collapse prevention systems substantially reduce the probability of collapse during Maximum Considered Earthquake (MCE) ground motions, depending on the building and collapse inhibiting mechanism deployed. Seismic hazard data suggests that collapse prevention systems would provide a $1 \%$ or less risk of collapse in 50 years in many locations, mostly in the central and eastern United States.
\end{abstract}

Keywords: FEMA P-695, FEMA P-58, collapse prevention, gravity systems

*Corresponding author. Tel.: 307-766-6142; fax: 307-766-2221. E-mail: jjudd5@ uwyo.edu 


\section{Introduction}

The current accepted practice in seismic resistant design of new buildings in the United States $[1,2]$ is to proportion and detail structures such that there is no more than a $10 \%$ probability that the structure will collapse when subjected to the risk-based Maximum Considered Earthquake ground motions $\left(\mathrm{MCE}_{\mathrm{R}}\right)$, which have a mean recurrence interval (MRI) of approximately 2,475 years. While no explicit calculations are required to assess the true likelihood of collapse performance, safeguards are provided by well-established system configuration and detailing rules and by limits on computed drift.

The expectations for new building performance subjected to ground motions that occur more frequently than the MCE are loosely stated in the commentary for current design standards (e.g. [1]), but no calculations are required to assess the adequacy of the building's performance under such motions. However, there is significant historical evidence that earthquakes along the west coast of the United States that occur more frequently than the MCE, and which produce less severe ground shaking than the MCE, can cause significant and unacceptable levels of damage. The 1994 Northridge California Earthquake, which caused an estimated \$57 billion in losses [3], is a case in point. This earthquake had a magnitude of 6.7 , and earthquakes of equivalent size are expected to reoccur once every 35 to 40 years in that area. Although it is technically incorrect to associate a single event with a return period, Northridge was one of many moderatemagnitude earthquakes that caused extensive economic loss in California during the span of only a few decades [4]. Thus, a significant shortcoming of the current practice for designing new buildings is that it does not explicitly address the lower hazard-level ground motions. 


\subsection{Performance-Based Design in the Central and Eastern United States}

A broadened seismic design philosophy called performance-based earthquake engineering has emerged as a potential remedy, where the goal is to meet or exceed predefined performance objectives under different levels of ground motion. Although there is general agreement for the recurrence intervals assigned to the Design Basis Earthquake (DBE), and the MCE level ground motion, various performance-based design provisions assign different recurrence intervals for lower (serviceability and immediate occupancy) level ground motion (see commentary on the International Performance Code [2]). These intervals can vary anywhere from a 25-year MRI to a 72-year MRI.

Performance-based design was developed based on the characteristics of tectonic plate boundaries, like the western United States, where it has been the experience that frequent and occasional earthquakes can be very significant, as was the case with Northridge. While this expectation is appropriate for the western United States, it is not necessarily correct in the central and eastern United States.

Differences between seismic ground shaking that occurs more frequently than the MCE are plainly evident in many regions and across a wide range of low-hazard levels [5]. For example, Fig. 1 shows spectral acceleration for the 72-year MRI compared to the MCE (2,475year MRI). The deterministic cap on ground motion used in ASCE 7-10 is not included. Fig. 1a compares the 0.2-sec spectral accelerations $\left(S_{S}\right)$, and Fig. 1b compares the 1.0-sec spectral accelerations $\left(S_{1}\right)$ using contour lines of constant values. Generally speaking, spectral demand with a 72 -year MRI, is approximately $10 \%$ or less of the MCE for the central and eastern United States, and $20 \%$ of the MCE for the western United States. The ratio for high-seismic regions in the central and eastern United States is much lower (1\% to $3 \%)$. 

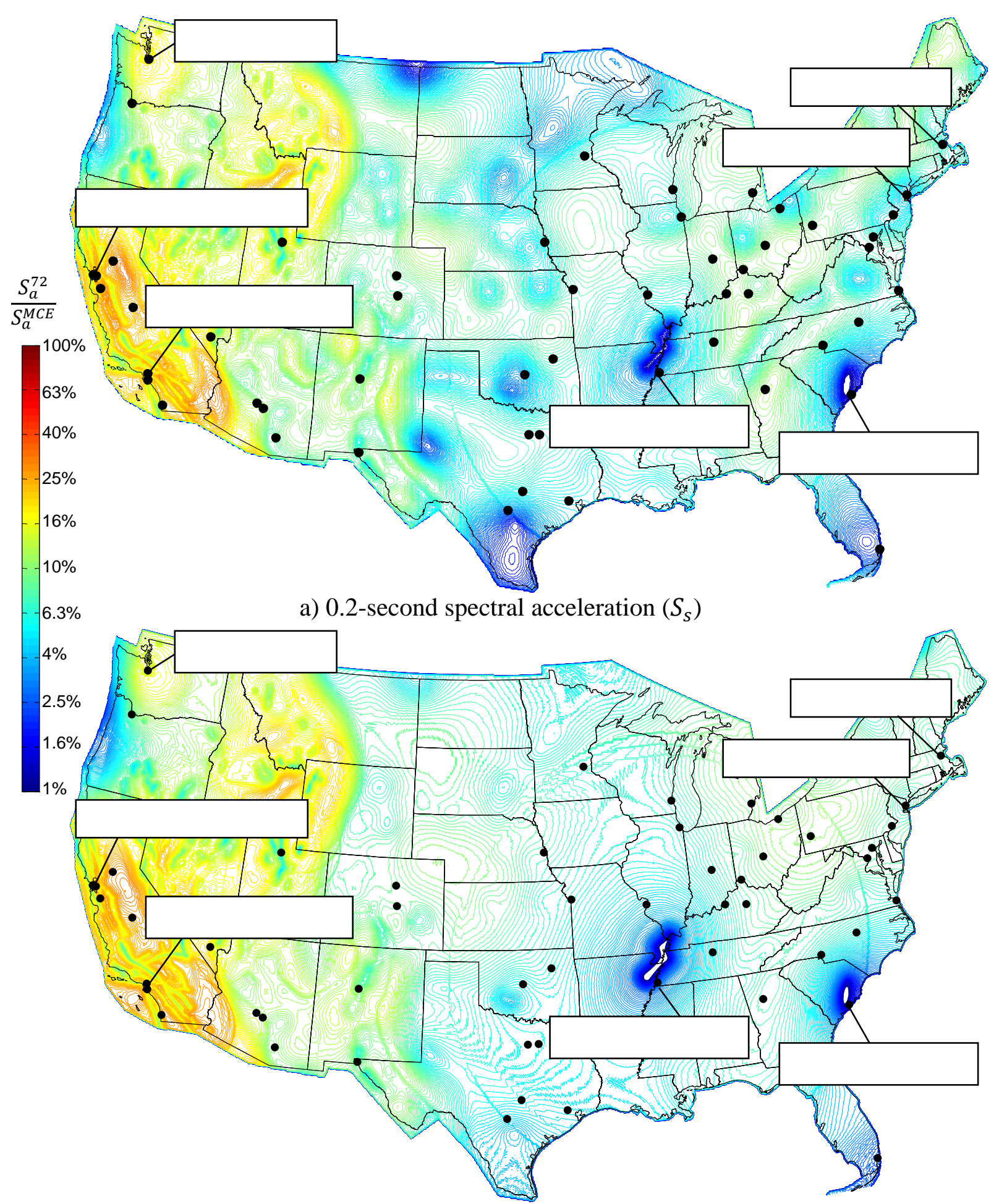

a) 1.0-second spectral acceleration $\left(S_{1}\right)$

Fig. 1. Ratio of 72-year MRI spectral acceleration compared to MCE (2,475-year MRI). 
Thus, the nature of the overall seismic hazard is quite different in the central and eastern United States. Large magnitude earthquakes are possible outside the west, but they are rare. The impact of this difference is illustrated in Fig. 2, which shows the probability over the next 100 years of a 6.7-magnitude earthquake occurring in Los Angeles, California compared to Charleston, South Carolina. The probability was calculated using the USGS 2009 earthquake probability mapping application [6]. The probability is extremely high in Los Angeles (as high as $100 \%$ in many regions), but is less than $15 \%$ in Charleston, and the probability rapidly diminishes as the distance from Charleston increases. In contrast to Los Angeles, a building in Charleston with an expected usable life of 100 years would have a very low probability of being damaged by ground shaking.

The implication is that in many areas of the central and eastern United States, the only seismic limit state of importance is collapse prevention. Ground shaking associated with more frequently occurring events is not likely to be damaging, and in fact, the gravity and wind system is going to be capable of resisting the most probable motions [7]. Of course it is not prudent to ignore the likelihood of a major earthquake, and collapse prevention is still essential.

Thus, while the goal of less than $10 \%$ probability of collapse given the MCE is equally applicable in both the western and the central and eastern United States, and the desire for good performance at lower level shaking is also equally applicable, it seems that the very distinct differences in the temporal distribution of the level of shaking in the different portions of the country would lead to different conceptual bases for providing acceptable performance. However, this is not the case because for a given ground motion intensity buildings in the central and eastern United States are designed in essentially the same manner as buildings in the western part of the country. 


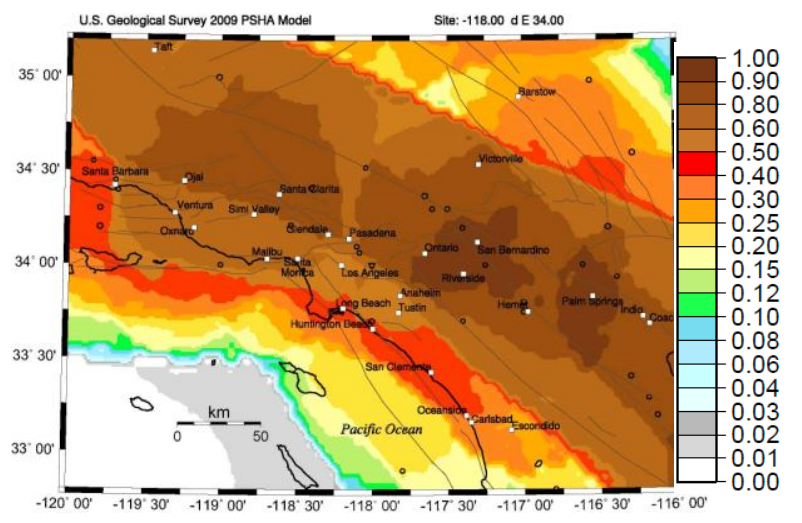

a) Los Angeles, California

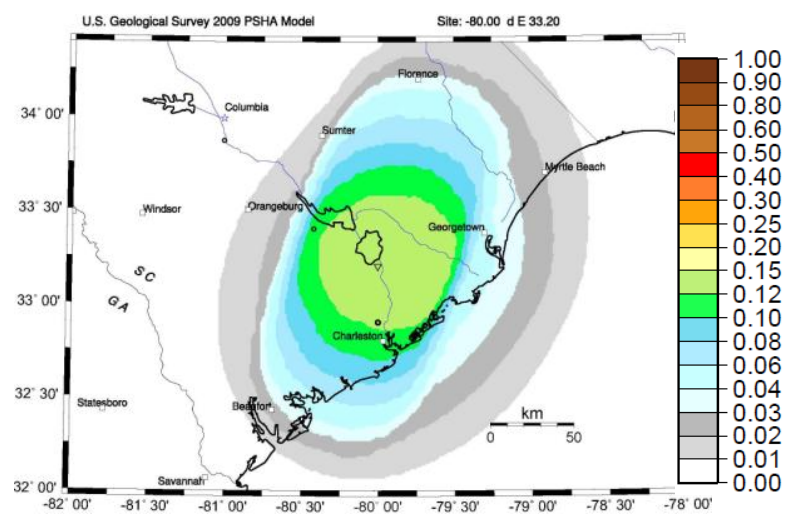

b) Charleston, South Carolina

Fig. 2. Probability of exceeding a 6.7-magnitude earthquake in 100 years.

\subsection{Objectives and Scope}

The objective of this study is to determine the potential for using a conventional main lateralforce resisting system, combined with the reserve strength in the gravity framing and collapseinhibiting mechanisms deployed throughout the building-termed a collapse-prevention system - to provide adequate serviceability performance and collapse safety in the central and eastern United States. While collapse prevention systems are applicable to building structures of all materials, the focus of this study is on structural steel-frame buildings using either non-ductile moment frames with fully-restrained directly welded flange connections not specifically detailed for seismic resistance, or ductile moment frames with reduced beam section (RBS) connections designed for moderate seismic demands. 


\section{Collapse-Prevention System Concept}

The concept of a collapse prevention system consists of two parts. First, the main lateral-force resisting system is designed for wind (or moderate to low seismicity), and together with the gravity framing system it is used to provide adequate performance under low to moderate level ground motions. Second, the main lateral-force resisting system and the reserve lateral strength in the gravity framing is used in tandem with a back-up collapse-inhibiting mechanism to provide life safety under extreme ground motions (i.e. the MCE level ground motions). Serviceability performance may be improved by augmenting collapse prevention systems with energy dissipation devices.

\subsection{Reserve Lateral Strength in Gravity Framing}

Gravity framing can serve as a reserve lateral system for two reasons: First, gravity frame connections have lateral strength. Composite concrete-slab and steel beam-to-column (shear tab) connections are partially restrained and inherently have lateral strength and stiffness. Liu and Astaneh-Asl [8,9] showed that simple gravity beam-to-column connections may provide significant lateral strength and act as a ductile back-up system by engaging the concrete slab. Similarly, reserve lateral strength also exists in braced frame systems where gusset plates at pinned ends of braces create rotational restraint at the beam-to-column connection [10,11].

Second, the quantity of gravity connections in a moment-frame building can be significant compared to the number of fully-restrained (moment) connections. Thus, although the strength of a partially restrained connection is typically a fraction of the moment-frame connection strength (on the order of $10 \%$ to $30 \%$ ), taken in aggregate the gravity framing strength may be significant. 
Analytical studies have shown that the gravity system may contribute in a significant way to the performance of steel moment frame structures, in terms of strength and stiffness [12], serviceability [13], and collapse resistance $[13,14,15]$. Incorporating the gravity system in a nonlinear response history analysis (at 3 times the MCE) of a 4-story building [15], for example, reduced median roof drift ratio from $4.9 \%$ to $3.4 \%$, and reduced number of collapses in 44 analyses from 22 to 11 . Post-earthquake reconnaissance has also confirmed the concept of reserve lateral capacity in gravity framing. Observations of two low-rise steel buildings after the 1994 Northridge quake concluded that the perimeter moment frames had failed, but the gravity framing prevented collapse [16].

The availability of reserve lateral strength in the gravity framing has led to the idea of using dual systems for lateral resistance, such as a conventional lateral force resisting system (i.e. a moment or braced frame) for primary resistance, and a gravity framing system as a back-up lateral resisting system $[17,18,19]$.

\subsection{Collapse Inhibiting Mechanisms}

Collapse inhibiting mechanisms consisting of slack cables have been used in the past, particularly in large-scale seismic laboratory experiments where conventional structures are tested to near collapse, but for safety and other reasons it is not acceptable for the test specimen to completely collapse. Added stiffness reduces the period of vibration, and in seismic design, when the period is in the constant velocity realm of the spectrum (period greater than $T_{S}$ ) this corresponds to an increase in the base shear demand. Thus, collapse inhibiting mechanisms that have delayed strength and stiffness are especially attractive. The intent of such a mechanism is to not add stiffness to the structure prior to the time the mechanism is needed. 
A variety of designs could form a collapse inhibiting mechanism. The simplest mechanisms consist of a pair of slack cables (Fig. 3a,b) or loose linkages (Fig. 3c) that provide no resistance or stiffness until the building story deformation reaches some limit, such as $2 \%$ interstory drift. Then, at the predefined deformation, the slack cable (SC) or loose linkages (LL) become taut and augment the residual building system strength to prevent dynamic instability.

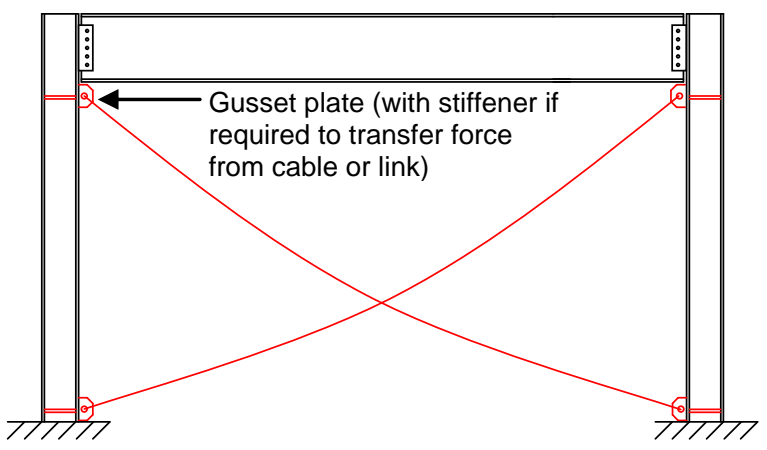

a) Full-bay slack-cable X-bracing

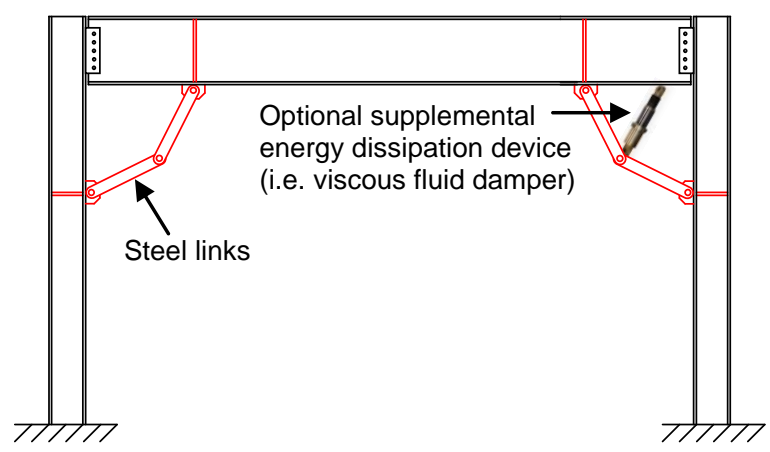

c) Loose linkages (LL)

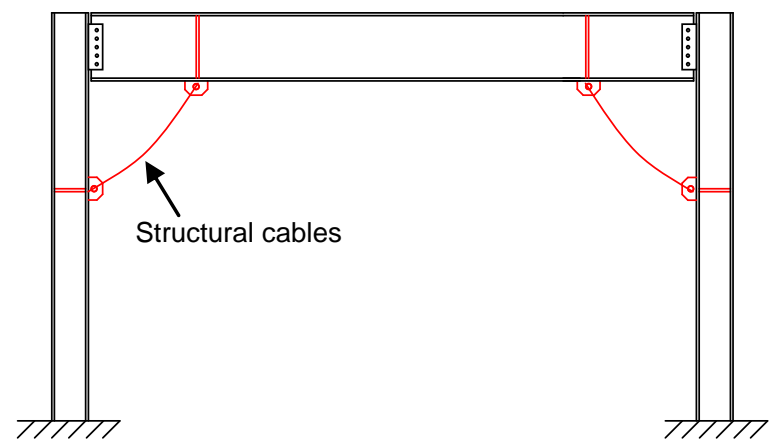

b) Slack-cable (SC) knee bracing

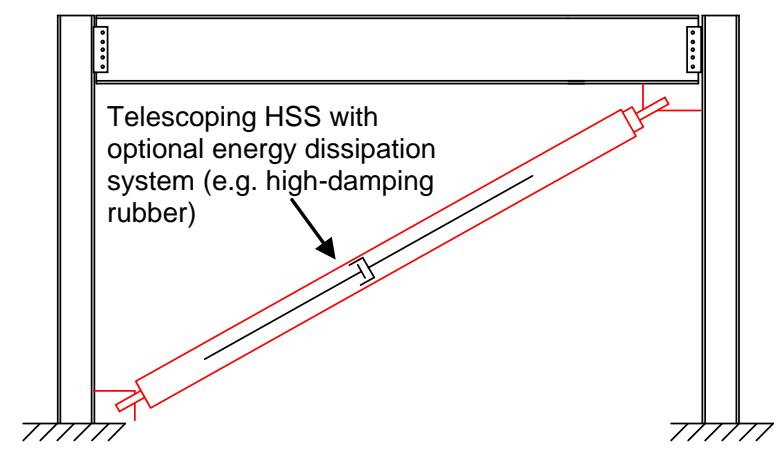

d) Telescoping brace (TB)

Fig. 3. Prototypical collapse inhibiting mechanisms. 
Selected mechanisms can be equipped with energy dissipating devices, such as small viscous fluid dampers or viscoelastic solid high-damping rubber material, to enhance serviceability performance under wind or small seismic events. A previous investigation of steel moment-frames buildings [20] indicated that adding even a small amount of damping is advantageous (e.g. increasing the equivalent system damping from 5\% to $10 \%$ critical). In the case of collapse prevention systems, this added damping would primarily be used to control behavior up until the point that the collapse inhibiting mechanism engages.

In fact, the loose-linkage mechanism can be thought of as a toggle brace without the damper. The idea behind a toggle brace is that deformations acting parallel to the braces are amplified in the transverse direction, thereby increasing the efficiency of the damper [21]. The loose linkages may be used alone as a collapse inhibiting mechanism (left corner in Fig. 3c) or may be used in association with a damper (right corner in Fig. 3c), to act as a true toggle brace damper system.

A more complex collapse inhibiting mechanism is the telescoping brace (TB) shown in Fig. 3d. In this mechanism two steel tubes telescope over each other and can elongate without resistance until a "stop" mechanism causes the brace to go into tension. The brace cannot carry compression. The telescoping brace described here is an adaptation of the hybrid passive energy dissipation device developed by Marshall and Charney [22,23,24].

A key aspect of the collapse prevention system concept is the size of the mechanisms: the slack-cable and loose-linkage configurations can be compact and unobtrusive. Where a compact configuration is used, the collapse inhibiting mechanisms could be distributed throughout the building. A larger mechanism, such as the telescoping brace, on the other hand, would likely be installed in only selected bays. Another important aspect of the collapse prevention system is 
that the mechanisms may be deployed in both the moment frame and the gravity frame. Indeed, collapse inhibiting mechanisms are envisioned to work as a supplement to the conventional lateral-force resisting system (e.g. moment frame or braced frame) and in conjunction with reserve lateral strength in the gravity framing system.

\section{Archetype Buildings}

The applicability of the collapse prevention system concept to steel moment-frame buildings commonly constructed in the central and eastern United States was determined using a set of archetypical short period (1-story and 2-story) and long period (4-story and 8-story) office buildings that employed either a non-ductile moment frame, or a ductile moment frame designed for moderate seismic demands. The building archetypes were developed following the procedure recommended in FEMA P-695 [25], and the building configuration and overall plan layout (Fig. 4), story heights, and gravity loads match the special steel moment framing building archetypes developed in the ATC-76 project [26].

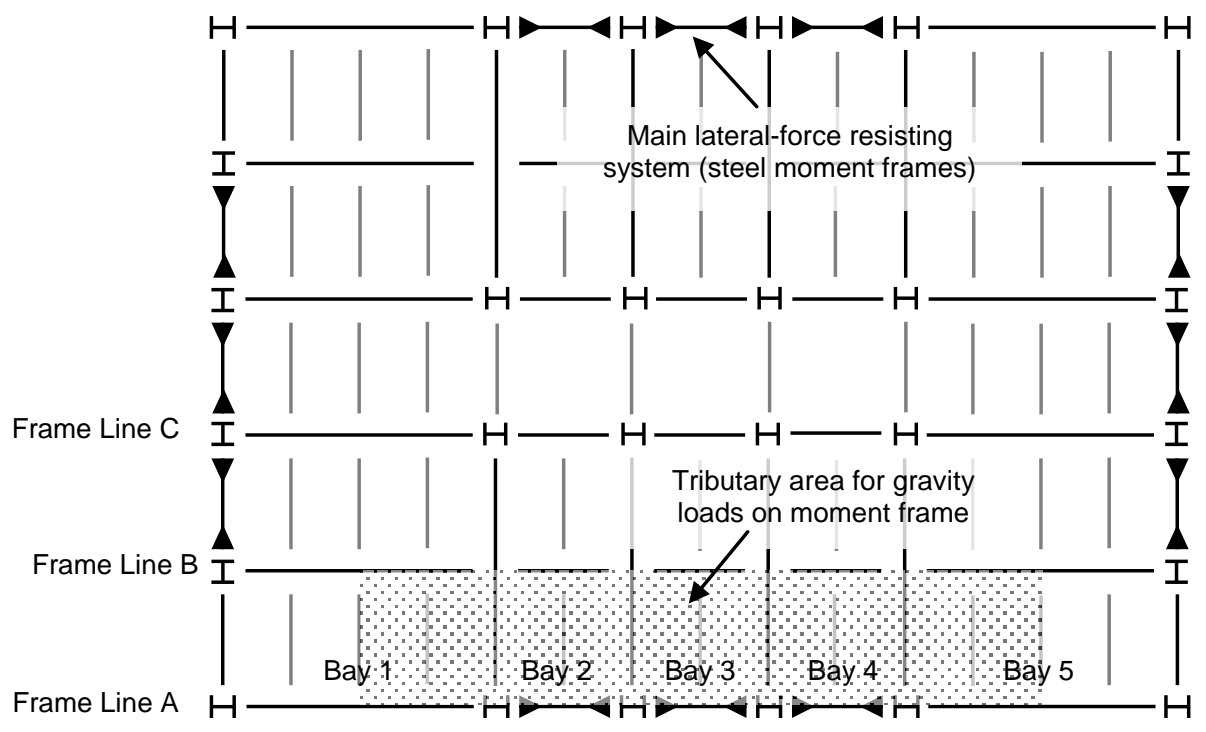

Fig. 4. Structural framing plan of archetypical buildings. 
The building plan used 20-ft (6.1-m) bays and perimeter moment frames. The first story height (measured to the top of the beam) was $15 \mathrm{ft}(4.6 \mathrm{~m})$. Upper story height was $13 \mathrm{ft}(4.0 \mathrm{~m})$. 1- and 2-story moment frame columns were considered pinned at the base, taller columns were considered fixed.

Gravity columns were considered pinned at the base, and were spliced $4 \mathrm{ft}$ (1.2 $\mathrm{m})$ above the third and sixth floors. The ATC-76 evaluation did not model gravity framing and, as a result, the gravity framing layout shown, including the direction and spacing of filler beams every $10 \mathrm{ft}$ (3.1 m), column splices, and gravity column orientation, were developed in this study. The gravity frame columns were oriented with the strong axis in the same direction as the moment frames (the longitudinal direction), and thus the reserve lateral strength observed in this study represents an upper bound on the gravity framing contribution for this building configuration.

Two types of main lateral-force resisting systems were evaluated for each building archetype. The first type consists of ductile special steel moment frames (SMF) with reduced beam section connections designed for the FEMA P-695 Seismic Design Category (SDC) $\mathrm{D}_{\min }$. The ductile moment frames were previously developed in the ATC-76 project, and the details of the design and member sizes are available in Appendix D of the ATC project report [26]. The second type consists of non-ductile steel moment frames not detailed for seismic resistance, so called " $R=3$ " moment frames, designed only for a wind hazard corresponding to non-coastal location in the United States and low seismicity $\left(\mathrm{SDC} \mathrm{B}_{\mathrm{min}}\right)$. By contrast, the ATC-76 project did not consider wind in the design of the ductile moment frames.

Table 1 provides the structural members for the non-ductile archetypical buildings. Moment frame design was based on meeting drift requirements and providing a column moment of inertia between 1 and 2 times the beam moment of inertia [27,28]. Initial beam and column 
sizes were adjusted when required to meet strength and stability requirements. Column sizes were selected from W14, W18, and W24 depending on the loads. To reduce cost, column sizes were increased to avoid specifying doubler plates.

Table 1. Member sizes for archetypical buildings with non-ductile moment frames.

\begin{tabular}{|c|c|c|c|c|c|c|c|c|c|c|}
\hline \multirow{2}{*}{\multicolumn{5}{|c|}{ Moment Frame }} & \multicolumn{6}{|c|}{ Gravity Frame } \\
\hline & & & & & \multicolumn{3}{|c|}{ Beam } & \multicolumn{3}{|c|}{ Column } \\
\hline \multirow{2}{*}{$\begin{array}{l}\text { No. of } \\
\text { stories }\end{array}$} & \multirow{2}{*}{ Story } & \multirow{2}{*}{ Beam } & \multicolumn{2}{|c|}{ Column } & Frame A & \multicolumn{2}{|c|}{ Frame C } & \multirow{2}{*}{$\begin{array}{l}\text { Frame A } \\
\text { Line 1, } 6\end{array}$} & \multicolumn{2}{|c|}{ Frame C } \\
\hline & & & Exterior & Interior & Bay 1, 5 & Bay 1, 5 & Bay 2, 3, 4 & & Line 2, 5 & Line 3,4 \\
\hline 1 & 1 & W18X35 & W14X82 & W14X82 & W24x68 & W24x68 & W16x31 & W14x43 & W14x90 & W14x61 \\
\hline & & & & & & & & & & \\
\hline \multirow{2}{*}{2} & 1 & W21X44 & W18X71 & W18X76 & W24x68 & W24x68 & W16x31 & W14x43 & W14x90 & W14x61 \\
\hline & 2 & W16X31 & W18X71 & W18X76 & W24x68 & W24x68 & W16x31 & W14x43 & W14x90 & W14x61 \\
\hline & & & & & & & & & & \\
\hline \multirow{4}{*}{4} & 1 & W16X40 & W18X76 & W18X86 & W24x68 & W24x68 & W16x31 & W14x43 & W14x90 & W14x61 \\
\hline & 2 & W21X44 & W18X76 & W18X86 & W24x68 & W24x68 & W16x31 & W14x43 & W14x90 & W14x61 \\
\hline & 3 & W18X35 & W18X40 & W18X46 & W24x68 & W24x68 & W16x31 & W14x30 & W14x90 & W14x61 \\
\hline & 4 & W16X31 & W18X40 & W18X46 & W24x68 & W24x68 & W16x31 & W14x30 & W14x90 & W14x61 \\
\hline & & & & & & & & & & \\
\hline \multirow{8}{*}{8} & 1 & W21X48 & W24X146 & W24X146 & W24x68 & W24x68 & W16x31 & W14x61 & W14x120 & W14x74 \\
\hline & 2 & W24X68 & W24X146 & W24X146 & W24x68 & W24x68 & W16x31 & W14x61 & W14x120 & W14x74 \\
\hline & 3 & W24X76 & W24X76 & W24X103 & W24x68 & W24x68 & W16x31 & W14x43 & W14x90 & W14x68 \\
\hline & 4 & W24X55 & W24X76 & W24X103 & W24x68 & W24x68 & W16x31 & W14x43 & W14x90 & W14x68 \\
\hline & 5 & W24X55 & W24X55 & W24X62 & W24x68 & W24x68 & W16x31 & W14×34 & W14x90 & W14x68 \\
\hline & 6 & W21X48 & W24X55 & W24X62 & W24x68 & W24x68 & W16x31 & W14x34 & W14x90 & W14x68 \\
\hline & 7 & W18X35 & W24X55 & W24X55 & W24x68 & W24x68 & W16x31 & W14×30 & W14x90 & W14x68 \\
\hline & 8 & W18X35 & W24X55 & W24X55 & W24x68 & W24x68 & W16x31 & W14x30 & W14x90 & W14x68 \\
\hline
\end{tabular}

\section{Analytical modeling}

Archetypical buildings were idealized using two-dimensional half-building models (Fig. 5) and OpenSees [29] finite element software. Structural framing members were modeled using a phenomenological (concentrated plasticity) approach. Beams and columns were represented using an assembly of rotational springs (zero-length elements) and elastic beam-column elements in series to simulate the potential for plastic behavior to be developed near the end of each member. Columns participating in the moment frame were idealized as fixed at the base (except 
the 1-story frames); all other columns were idealized as pinned. Column splices (at story 3 and story 5) were modeled as a pinned connection (no rotational stiffness). Second-order (P- $\Delta$ ) effects were included using the "corotational" approach, where the local element frame continuously rotates with the element to capture large displacements, and small-strain constitutive relationships are applied.

\subsection{Moment frame beam-to-column connections}

The moment-rotation behavior of ductile beam-to-column connections (Fig. 6a) was represented using the Bilin uniaxial material with parameters based on regression analysis of test data [30]. The moment-rotation behavior of the non-ductile beam-to-column connections (Fig. 6b) was represented using the Pinching4 and MinMax uniaxial materials in OpenSees, with loaddeformation and hysteresis parameters based on FEMA P-440A [31], ASCE 41 [32], and FEMA $355 \mathrm{D}[33]$.

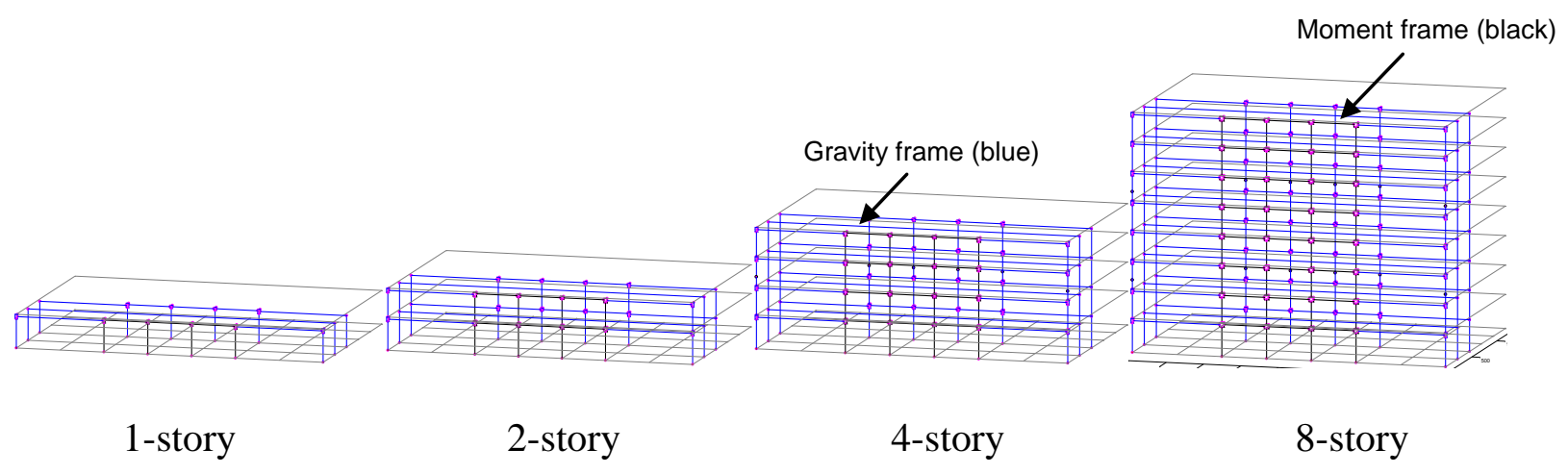

Fig. 5. Perspective view of analytical (half-building) models. 


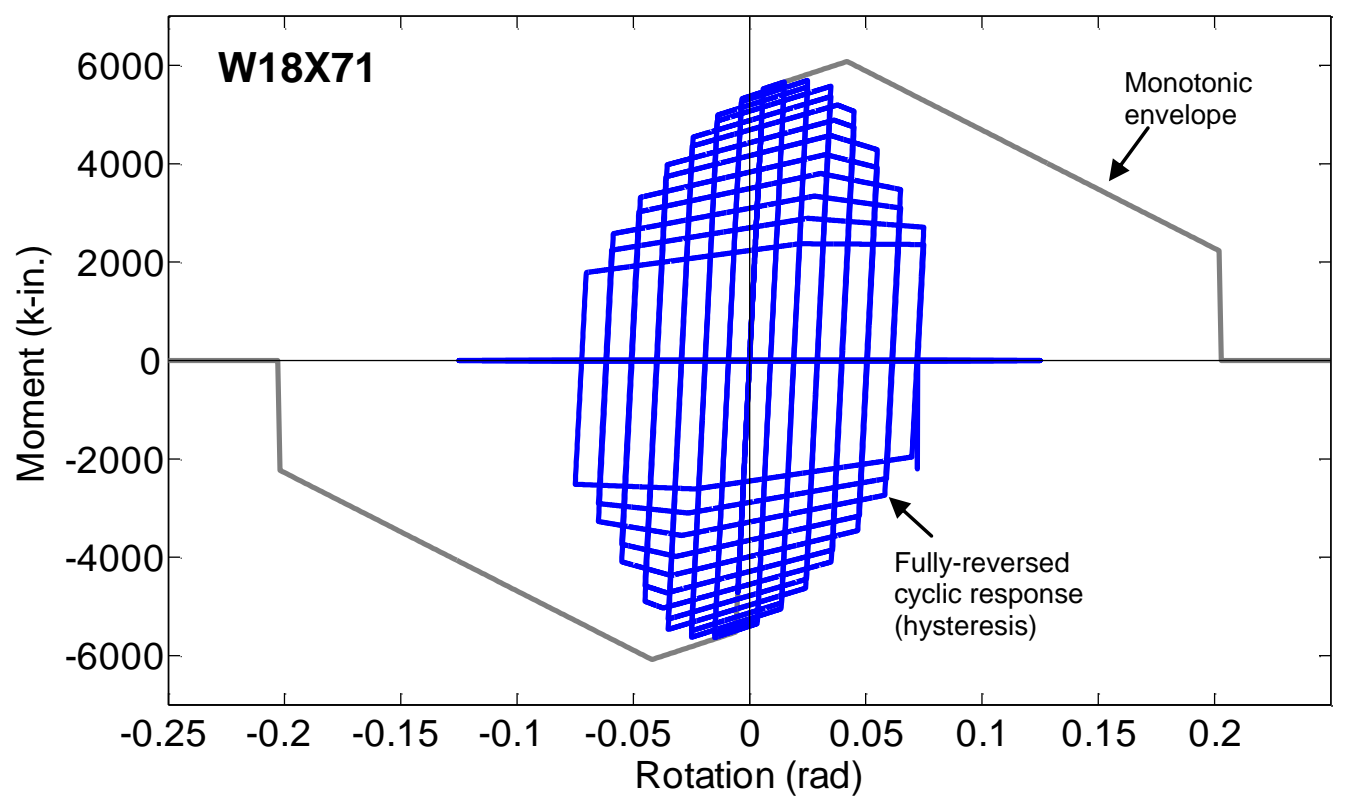

a) Ductile

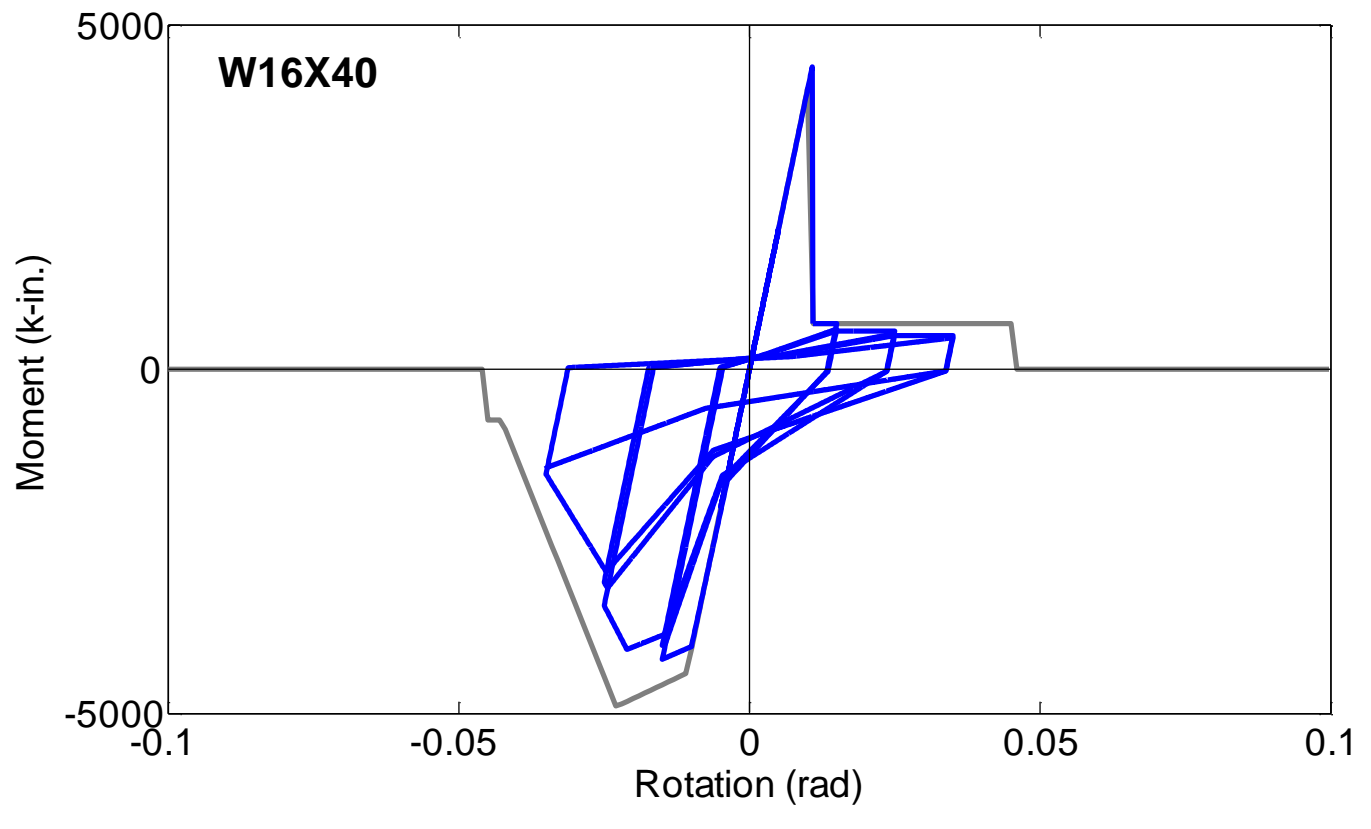

b) Non-ductile

Fig. 6. Idealized behavior for a typical fully-restrained beam-to-column connection. 
The non-ductile with fully-restrained directly welded flange connections lose strength immediately after yielding in positive moments (simulating fracture of the bottom flange) and more gradually in negative moments. The connections exhibit cyclic degradation of both stiffness and strength, within a 15\% residual strength boundary until approximately $4 \%$ drift, after which the rotational stiffness and flexural strength of the connection is zero. Although the effect of composite action between the beam and the concrete slab has been shown to generally enhance the seismic behavior of ductile connections [34,35], the influence on non-ductile connections has not yet been determined. As a result, in this study composite action was not included.

\subsection{Gravity frame beam-to-column connections}

The moment-rotation behavior for shear-tab connections (Fig. 7) was based on test data of shear tab connections [36], corresponding analytical models [37,38], and FEMA P-440A. The shear tab connection behavior is asymmetric due to the effect of composite action with the concrete slab. The connections exhibit cyclic degradation of both stiffness and strength, until approximately $10-12 \%$ drift, after which the rotational stiffness and flexural strength of the connection is zero.

The negative-moment capacity boundary (monotonic envelope) was based on the behavior of the bare steel beam. Experimental data and finite element analyses [38] show that a linear-elastic stress distribution is developed at the negative yield moment (Eq. 1), and a uniform plastic stress distribution is developed at the negative ultimate moment (Eq. 2), based on the geometry of the shear tab connection (where $d_{s t}$ is the height of the shear tab and $t_{s t}$ is the thickness of the shear tab). 


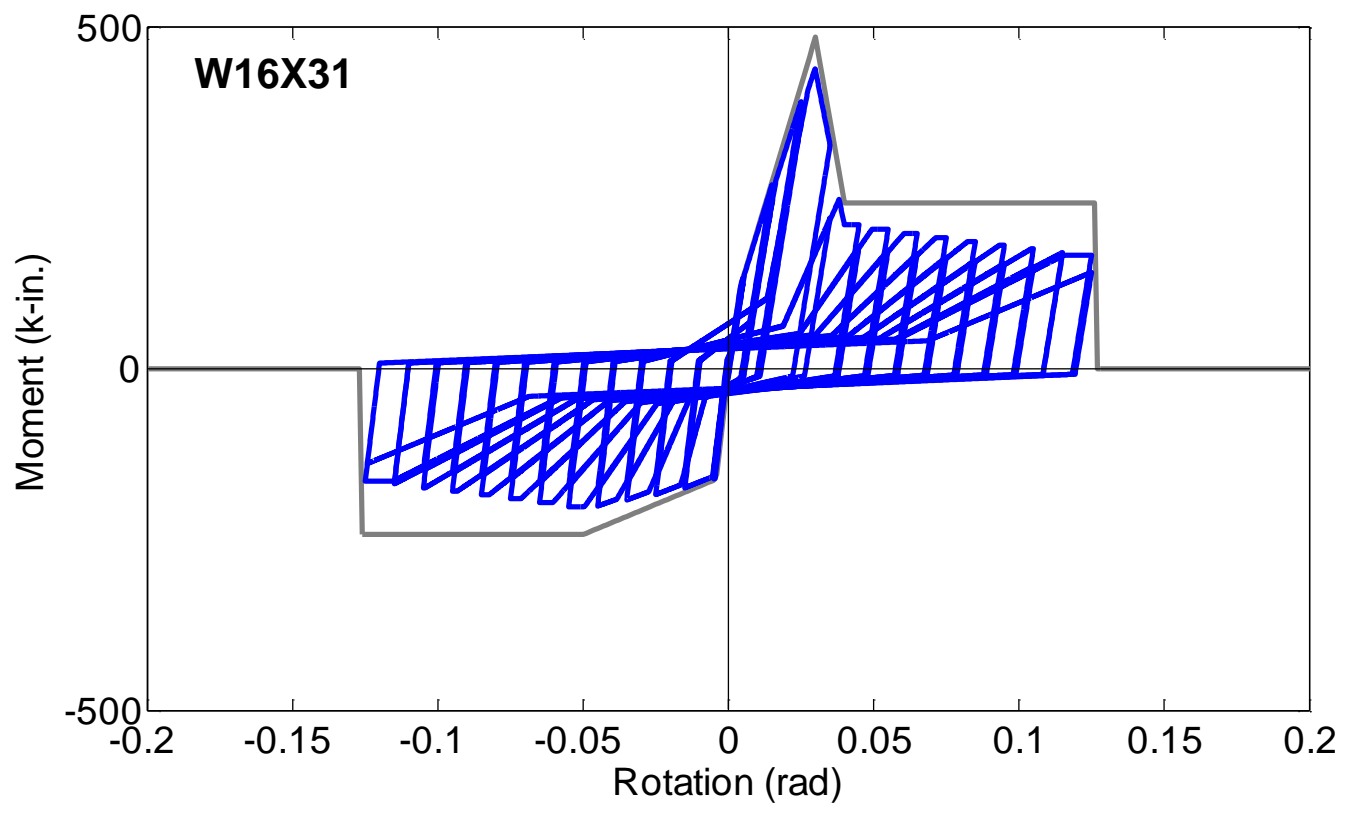

Fig. 7. Idealized behavior for a typical shear-tab beam-to-column connection.

$$
\begin{aligned}
& M_{y}{ }^{-}=\frac{1}{6} d_{s t}{ }^{2} t_{s t} F_{y} \\
& M_{u}{ }^{-}=\frac{1}{4} d_{s t}{ }^{2} t_{s t} F_{y}
\end{aligned}
$$

The positive-moment capacity boundary was based on observations of experimental data [37] that indicate maximum strength for positive moment (Eq. 3) is twice that for negative moment, and positive-moment yield strength (Eq. 4) is a quarter of maximum strength.

$$
\begin{aligned}
& {M_{y}{ }^{+}}=0.25 M_{u}^{+} \\
& M_{u}^{+}=2{M_{u}}^{-}
\end{aligned}
$$

The total (ultimate) rotational capacity (Eq. 5) for positive and negative moment was based on the gap, $g$ between the beam flange and the column, and distance from the mid-height of the shear tab to the beam flange, $d[37]$. 


$$
\theta_{\text {Total }}=\frac{g}{d / 2}
$$

Cyclic behavior including degradation of stiffness and strength was incorporated using a tri-linear loading and unloading rule-based hysteresis model [39], where, relative to the maximum historic demand and strength developed, the ratio of the deformation at which reloading occurs was 0.5 , the ratio of the force at which reloading begins was 0.25 , and the ratio of strength developed upon unloading was 0.05, as used in FEMA P-440A.

\subsection{Columns}

Column behavior was idealized similarly to beam behavior, except column plastic hinging moment-rotation behavior (Fig. 8a) was represented using the Bilin uniaxial material with parameters based on regression analysis of test data [30], and with an approximate reduction to account for axial load interaction. The reduction was based on AISC 360-10 Equations H1-1a and H1-1b [40] using a constant axial load resulting from the gravity load plus half the lateral load calculated in a nonlinear static (pushover) analysis. Column panel zones were explicitly represented using the Krawinkler joint model [41]. The shear-distortion behavior of column panel zones (Fig. 8b) was represented using the Hysteretic uniaxial material option. 


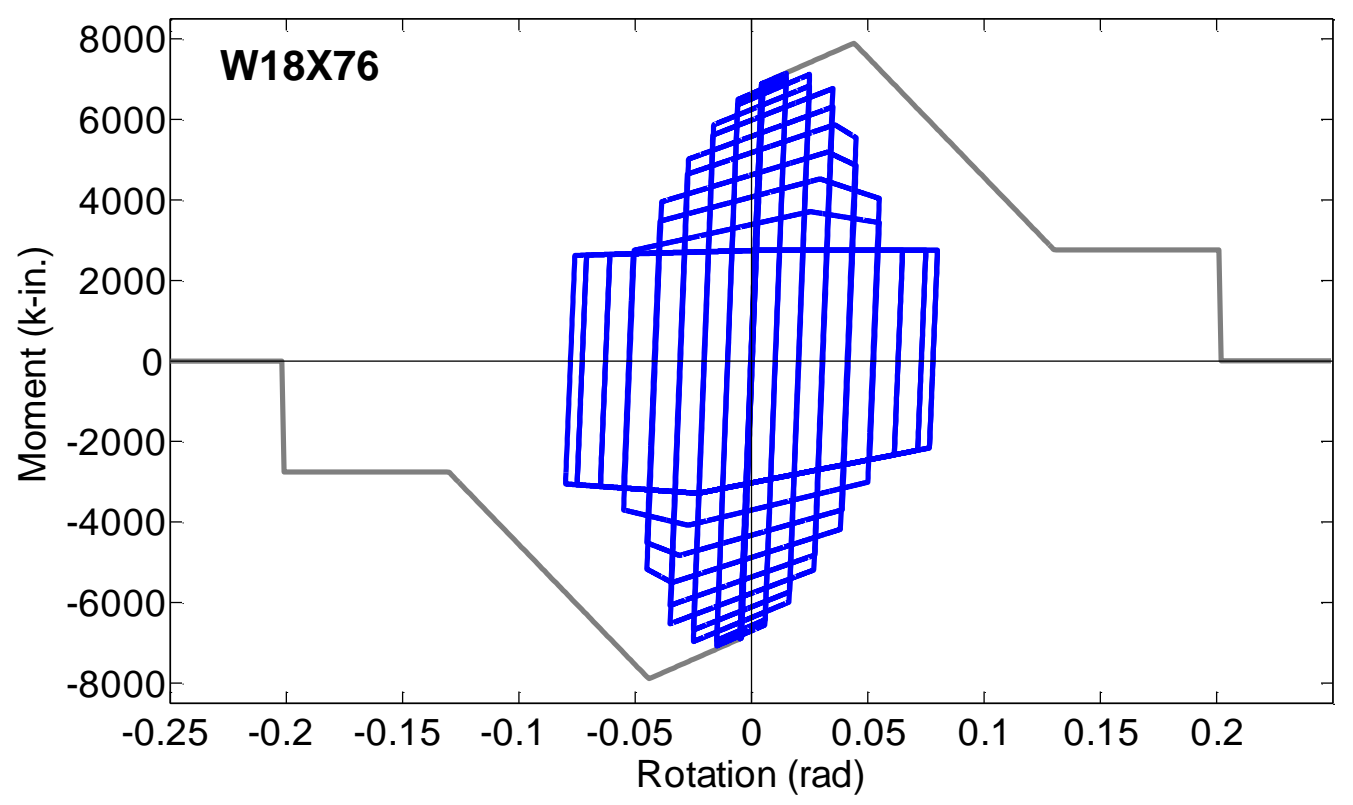

a) Column plastic hinge

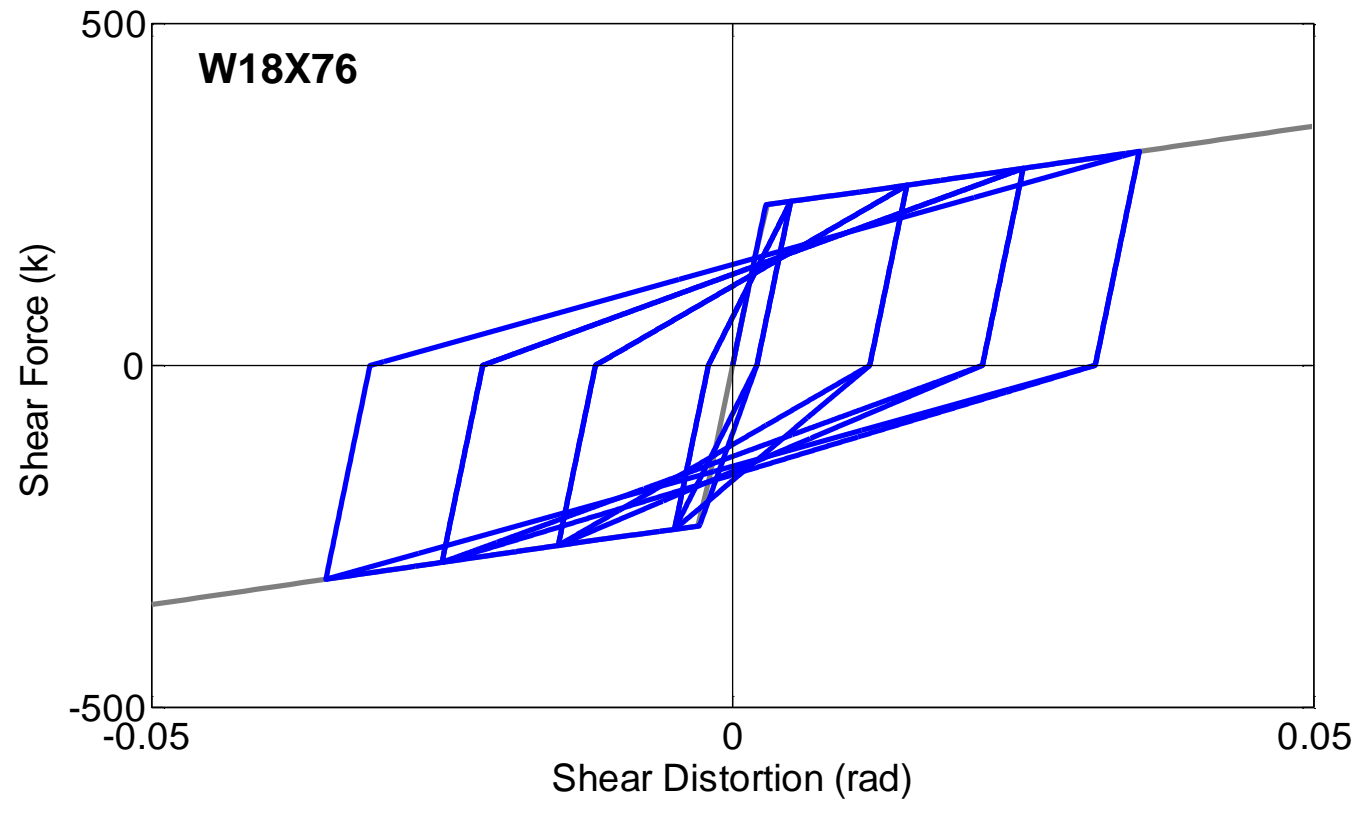

b) Panel zone distortion

Fig. 8. Idealized behavior for a typical column. 


\subsection{Collapse prevention system components}

Slack-cable collapse inhibiting mechanisms were represented using truss elements with a multilinear elastic material behavior (to simulate initial slackness) until fracture at the cable breaking load. The loose-linkage collapse inhibiting mechanism was represented using corotational truss elements that are elastic until fracture, approximated as the tensile yield limit state of the links. Energy dissipating devices (small viscous fluid dampers or viscoelastic solid high-damping rubber) were idealized using viscous corotational truss elements.

The formation of a plastic hinge in the column or beam at the location of the cable or link connection was precluded by limiting the axial capacity of the cable or link. The limiting capacity was based on two limit states: (1) interaction of axial load and moment at the location of the brace-to-column or brace-to-beam connection, as described in AISC 360-10 section H1.1; (2) shear yielding of the column or beam web, as described in AISC 360-10 section G2.1. The size of the collapse prevention system component was based on the lower value obtained according to the two limit states for either the beam or column.

The nominal axial strength, $P_{n}$ was determined according to AISC 360-10 section E3. The column effective flexural strength, $M_{n}$ was calculated by increasing the expected plastic moment, $M_{p}$ (Eq. 6) to account for isotropic hardening by the ratio $M_{y} / M_{p}$ and average strain hardening by the ratio $M_{c} / M_{y}$ (Eq. 7) based information extracted from a database of experimental testing of steel components [30].

$$
\begin{aligned}
& M_{p}=R_{y} F_{y} Z \\
& M_{n}=\left(\frac{M_{c}}{M_{y}}\right)\left(\frac{M_{y}}{M_{p}}\right) M_{p}
\end{aligned}
$$


The nominal flexural strength at each end was reduced to account for flexure and axial load, $P$ interaction, as previously discussed. The nominal flexural strength at the connection location, $M_{n}$ was determined according to AISC 360-10 section F2 and adjusted according to the moment gradient using the lateral-torsional buckling modification factor, $C_{b}$, as follows:

$$
\begin{aligned}
C_{b} & =1.60 \text { for double curvature } \\
& =1.36 \text { for single curvature }
\end{aligned}
$$

The interaction of axial load and moment at the location of the brace-to-column or braceto-beam connection was determined using AISC 360-10 section H1.1 (Eq. 8) based on the axial and moment force diagram shown in Fig. 9.

$$
1=\alpha \frac{\left(P-F_{y}\right)}{P_{n}}+\beta \frac{\left(M_{a}+M_{x}\right)}{M_{n}}
$$

where

$$
\begin{aligned}
& \alpha=\left\{\begin{array}{lc}
0.5 & \text { if }\left(P-F_{y}\right) / P_{n}<0.2 \\
1.0 & \text { otherwise }
\end{array}\right. \\
& \beta=\left\{\begin{array}{lc}
1.0 & \text { if }\left(P-F_{y}\right) / P_{n}<0.2 \\
8 / 9 & \text { otherwise }
\end{array}\right.
\end{aligned}
$$
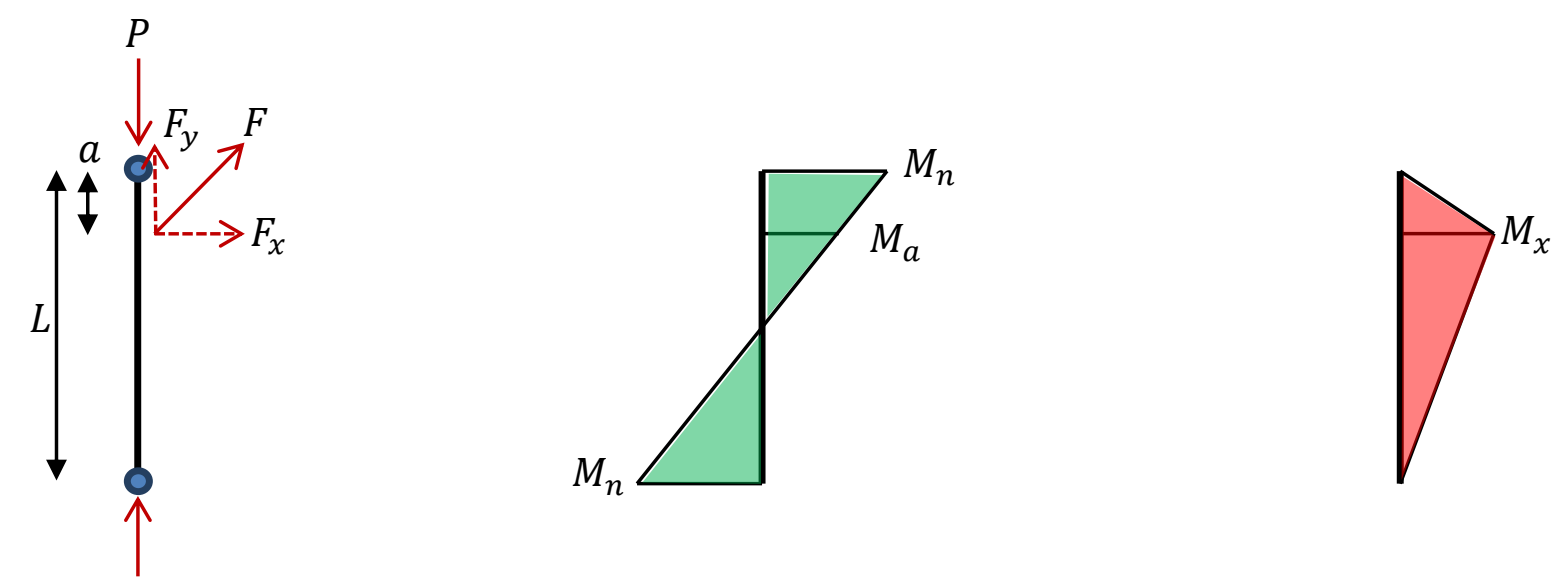
a) Structural member
b) Moments due to double curvature
c) Moments due to device

Fig. 9. Axial and moment forces on column with cable or link 
The maximum capacity of the cable or link, for interaction of axial and moment, was then backcalculated using (Eq. 11):

$$
F_{\max 1}=\frac{P_{n} M_{n}-\alpha M_{n} P-\beta P_{n} Q M_{n}}{\left[\frac{\beta P_{n} a(L-a)}{L \sqrt{2}}\right]-\frac{\alpha M_{n}}{\sqrt{2}}}
$$

where

$$
Q=\left\{\begin{array}{cc}
(L-2 a) / L & \text { double curvature } \\
(L-a) / L & \text { single curvature }
\end{array}\right.
$$

Shear yielding of the column or beam web was determined using AISC 360-10 section G2.1, $V_{n}=0.6\left(F_{y} R_{y}\right) A_{w}$, where $A_{w}$ is the area of the web. Ultimately, the lowest value of the two limit states (minimum of $V_{n} \sqrt{2}, F_{\max 1}$ ) was used to size the cable or link.

In the archetypical buildings, slack-cable and loose-linkage mechanisms were deployed in bays 1 to 5 along frame A, and in bays 2 to 4 along frame C. Full-bay slack-cable $\mathrm{X}$ bracing was not included in this study. Telescoping brace mechanisms were used in bays 2 and 4 along frame A. Using the capacity based design described, the structural cables ranged from 21-mm dia. and $79 \mathrm{k}(351 \mathrm{kN})$ breaking force, to $45-\mathrm{mm}$ dia. and $434 \mathrm{k}(1,930 \mathrm{kN})$ breaking force, with properties based on Ronstan Galfan full-locked structural cables (www.ronstan.com). The links consisted of A992 steel bars with an effective net area that ranged from $1.0 \mathrm{in}^{2}\left(645 \mathrm{~mm}^{2}\right)$ to 8.4 in. $^{2}\left(5,420 \mathrm{~mm}^{2}\right)$. The telescoping brace (9x9x1/4 HSS A1085) area was 8.03 in. $^{2} .\left(5,180 \mathrm{~mm}^{2}\right)$. The expected yield strength was used, but no material overstrength was included. (Where applicable, overstrength can be included by reducing the allowable breaking force accordingly.)

A nonlinear static (pushover) analysis was used to determine the target drift at which collapse inhibiting mechanisms become engaged, typically between $2 \%$ to $4 \%$. When utilized, energy dissipating devices (small viscous fluid dampers or viscoelastic solid high-damping 
rubber) were sized to provide $10 \%$ equivalent system damping, based on a log-decrement of a free-vibration.

Fig. 10a shows the contribution the moment frame (MF), gravity frame (GF), and slack cable (SC) mechanism to the pushover response of the 4-story ductile-frame building. The slack-cables engage at approximately $2 \%$ drift, and the cables fail at approximately $6 \%$ drift. The pattern of collapse prevention component failure depends on the loading and archetype building. For example, the sequence of mechanism failures is described in Fig. 10b for the loose-linkage (LL) mechanism. At $4 \%$ drift, the initial linkage failure occurs in story 1 of the gravity frame. At $6 \%$ drift, five additional linkage failures occur in both the moment and gravity framing. Just prior to $7 \%$ drift, 14 linkages pairs have failed and a building collapse mechanism forms at story 2. The story-2 collapse mechanism was formed in this building model regardless of the inclusion of gravity frame reserve lateral strength or collapse inhibiting mechanism deployed.

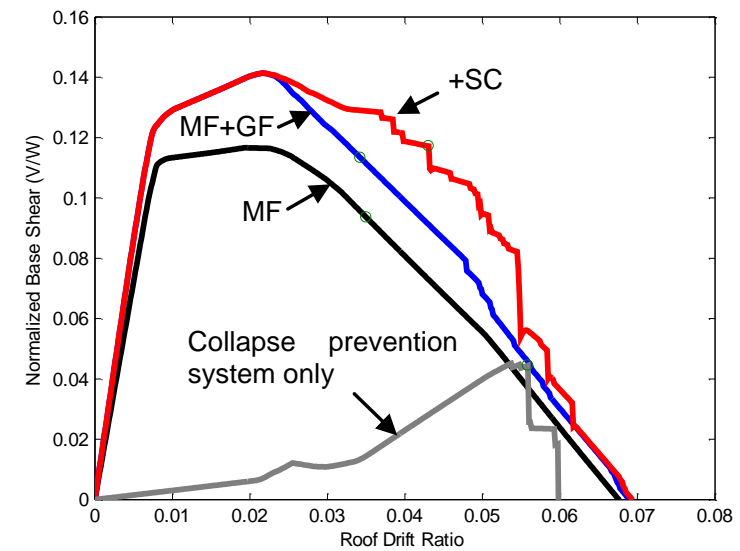

a) Effect of gravity framing and slack cable

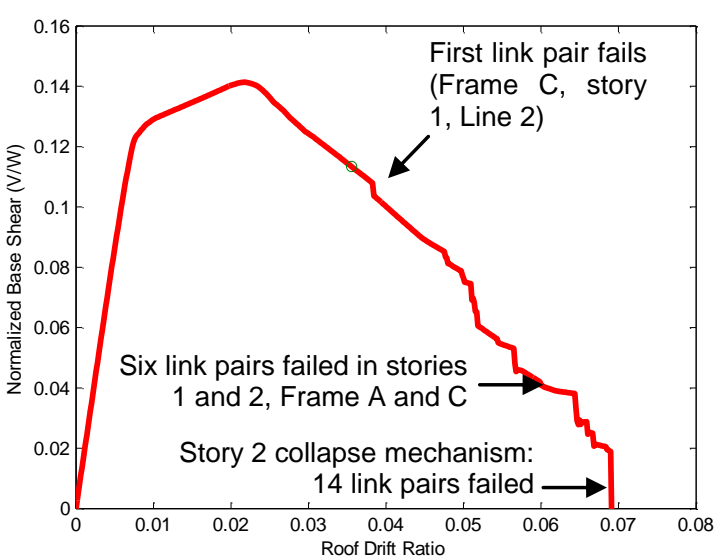

b) Effect of loose links

Fig. 10. Effect of collapse prevention system on pushover response of ductile 4-story building. 


\section{Collapse Assessment}

The probability of building collapse given the MCE was assessed using the FEMA P-695 methodology with two adaptations appropriate for the collapse prevention systems approach and for the central and eastern United States. First, the computed (model) fundamental period of vibration was used for both referencing spectral accelerations and for estimating the inherent damping (taken as $2.5 \%$ ) in the building that was not explicitly modeled through component hysteresis. Second, incremental dynamic analyses were run until all ground motions caused collapse and the measured record-to-record dispersion was used when incorporating uncertainty.

The collapse assessment consisted of several analysis procedures. An eigenvalue analysis and nonlinear static (pushover) analyses were completed first to determine the reference period of vibration for scaling reference and damping, to determine the axial loads used in the column plastic hinge approximation, to apply gravity loads, and to determine period-based ductility. Second, nonlinear dynamic response history analyses were completed.

The basic process of assessing collapse is illustrated in Fig. 11 through Fig. 13 for the 4story building with non-ductile moment frames. The FEMA P-695 "Far-Field" ground motion set was collectively scaled so that the median response spectrum matched the target spectrum $\left(\mathrm{SDC} \mathrm{D}_{\max }\right)$ at the reference period. Fig. 11a shows the scaled response spectra for the momentframe and gravity-frame $(\mathrm{MF}+\mathrm{GF})$ archetype model.

Each building model was then subjected to the ground motion set in successive incremental analyses until collapse, assumed to occur when the maximum interstory drift ratio is 0.2 or greater. Fig. $11 \mathrm{~b}$ shows the interstory drift response at each story of the moment-frame (MF) model at the collapse intensity for the 1994 Northridge earthquake Canyon Country Component 1 (LOS000) record. 


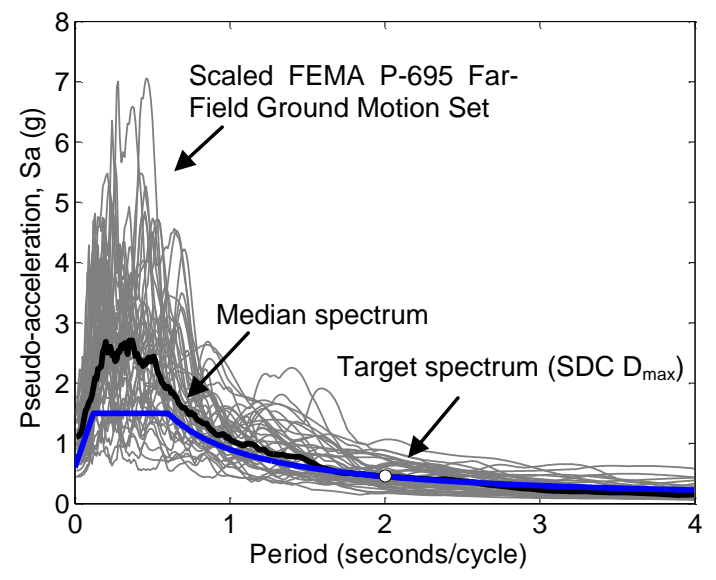

a) Scaled response spectra

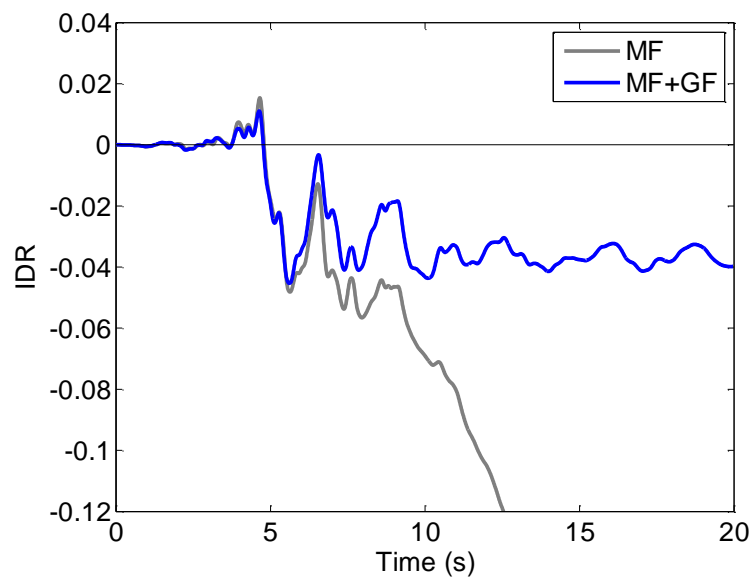

c) Story 2 drift history for LOS000, $S_{a}=0.36 \mathrm{~g}$

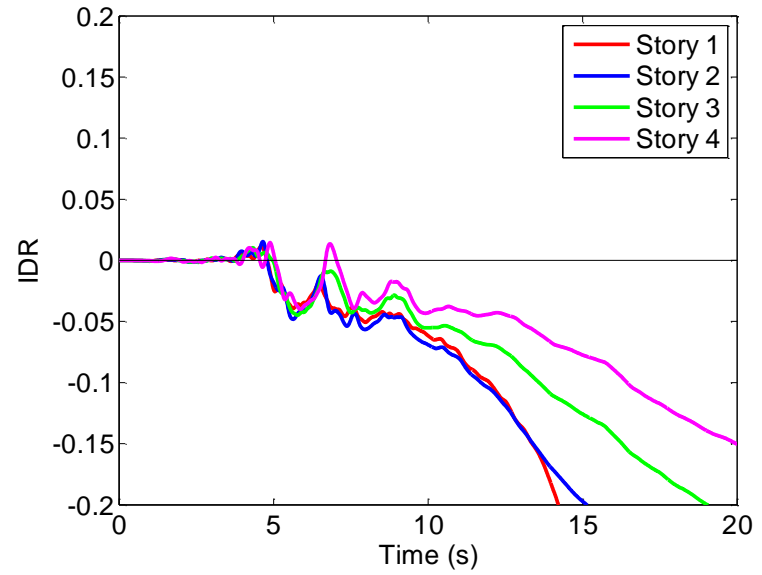

b) Drift history for LOS000, $S_{a}=0.36 \mathrm{~g}$

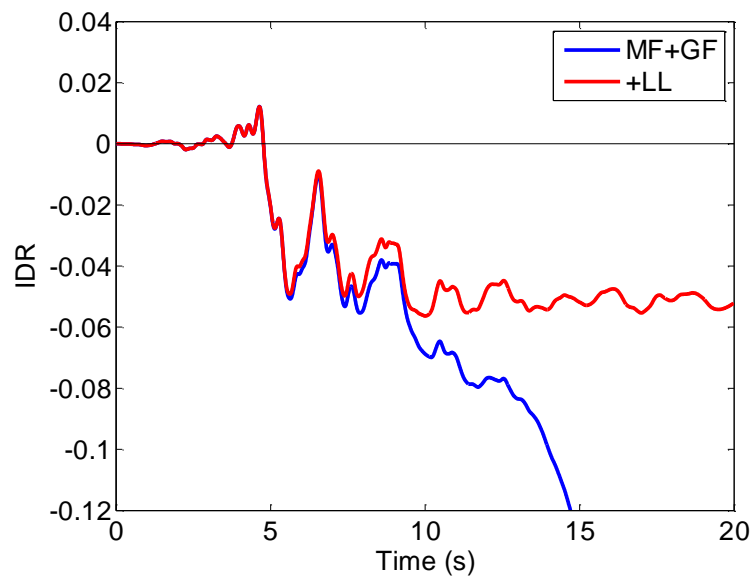

Fig. 11. Typical response of 4-story building with non-ductile moment frames.

Fig. 11c compares the response history of the MF and MF+GF models and shows that the reserve lateral strength in the shear-tab connections prevents collapse at $S_{a}=0.36 \mathrm{~g}$. Fig. $11 \mathrm{~d}$ compares the $\mathrm{MF}+\mathrm{GF}$ response to the same building model incorporating loose-linkages (+LL). For this ground motion record, the collapse prevention system prevents collapse at $S_{a}=0.39 \mathrm{~g}$. Fig. 12 shows the response of the 4-story building with non-ductile moment frames at $S_{a}=0.36$ g. Fig. 12a compares the deformed configurations of the MF, MF+GF, and +LL models. At this 
shaking intensity, the reserve strength in the shear tab connections is sufficient to prevent collapse.

The addition of the back-up mechanism (loose-linkages) prevents failure of the nonductile beam-to-column connection (Fig. 12b) in the first story. The behavior of a typical shear tab connection (Fig. 12c) and a typical column panel zone (Fig. 12d) is shown for the three models. The +LL model reduces building side-sway and utilizes less ductility in the shear-tab connection, which leads to increased panel zone deformations.

Fig. 13a shows individual incremental dynamic analysis (IDA) curves representing the response of different building models to the same ground motion record. The spectral acceleration (for the MF+GF building) corresponding to $S D C D_{\max }$ and $D_{\min }$ is shown for reference. In contrast, Fig. 13b shows the IDA curves for the entire ground motion set for one (MF+GF) building model. The median spectral acceleration at collapse (red line) is shown relative to the $\mathrm{SDC} \mathrm{D}_{\max }$ spectral acceleration (black horizontal line).

Collapse fragility curves were determined by fitting individual collapse points (spectral acceleration at the reference period and corresponding probability of collapse for one scaled ground motion record) with a curve assuming a lognormal distribution. Fig. 14a compares the collapse fragility curves for the $\mathrm{MF}, \mathrm{MF}+\mathrm{GF}$, and the same building model incorporating slackcables (+SC). Only measured (record-to-record) dispersion, $\beta_{R T R}$ in the response history analysis is shown in Fig. 14a. The median collapse spectral acceleration was adjusted (increased) to account for spectral shape based on period-based ductility, $\mu_{T}$ (FEMA P-695, Appendix B), and the total dispersion, $\beta_{\text {Total }}$ in collapse capacity was calculated using Eq. 13 .

$$
\beta_{\text {Total }}=\sqrt{{\beta_{R T R}^{2}+\beta_{D R}^{2}+\beta_{T D}^{2}+\beta_{M D L}^{2}}^{2}}
$$




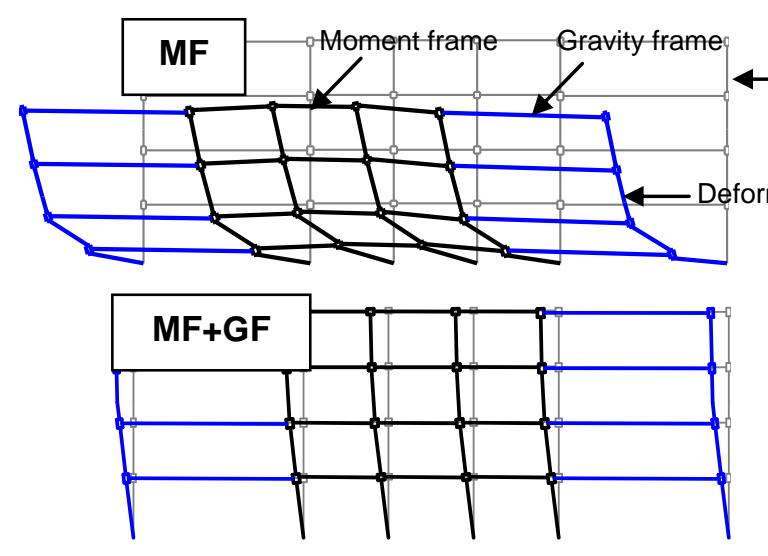

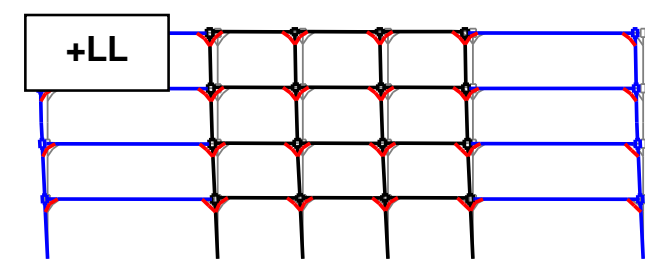

a) Perimeter frame configuration

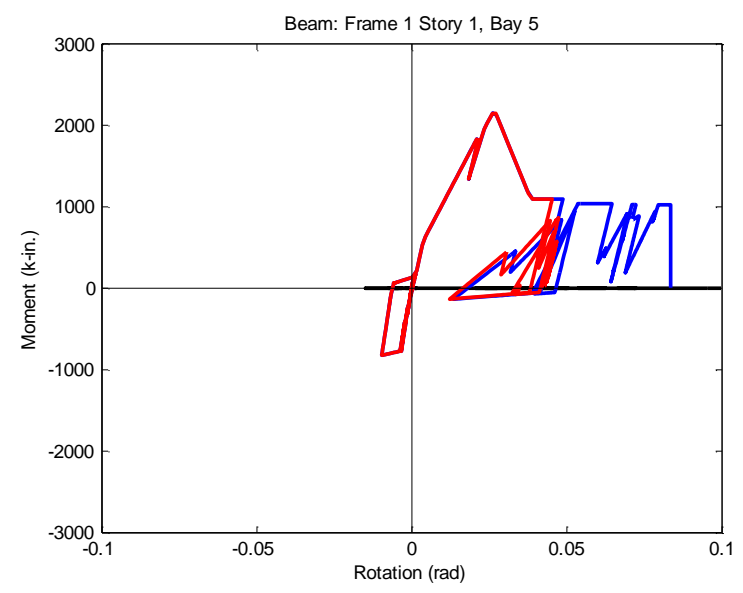

c) Shear-tab connection

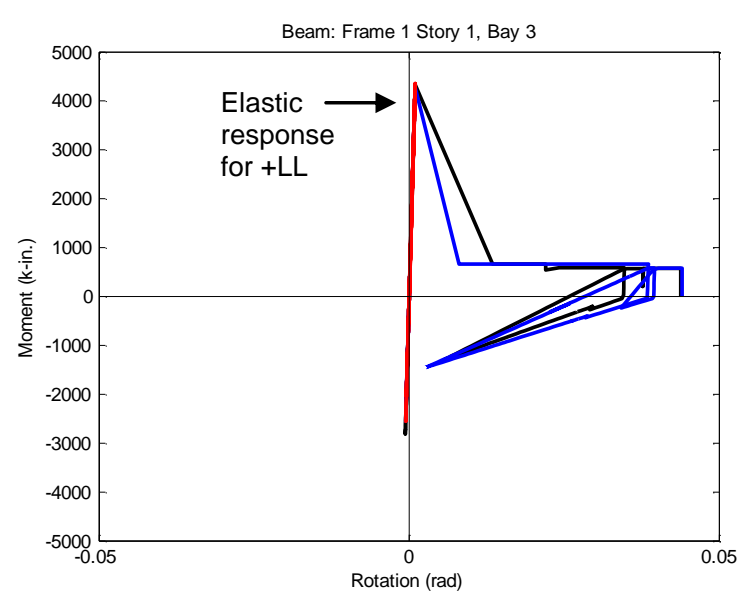

b) Non-ductile connection

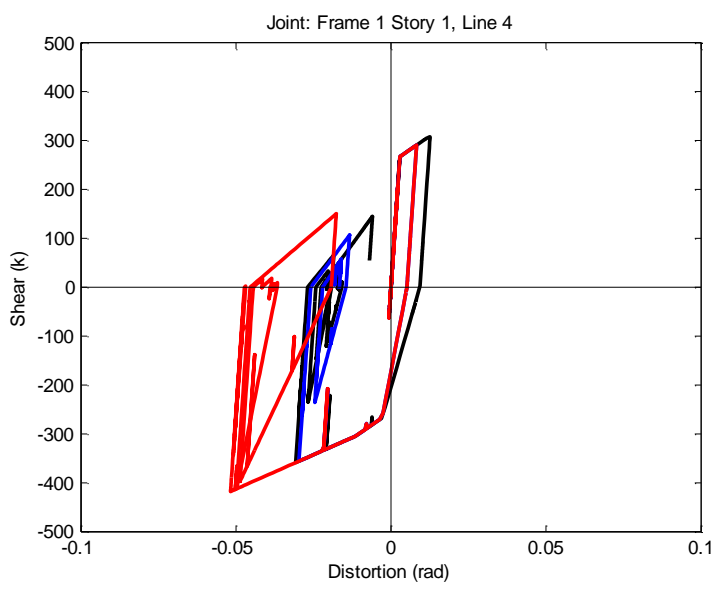

d) Column panel zone

Fig. 12. Response of 4-story building with non-ductile moment frames for LOS000, $S_{a}=0.36 \mathrm{~g}$. 


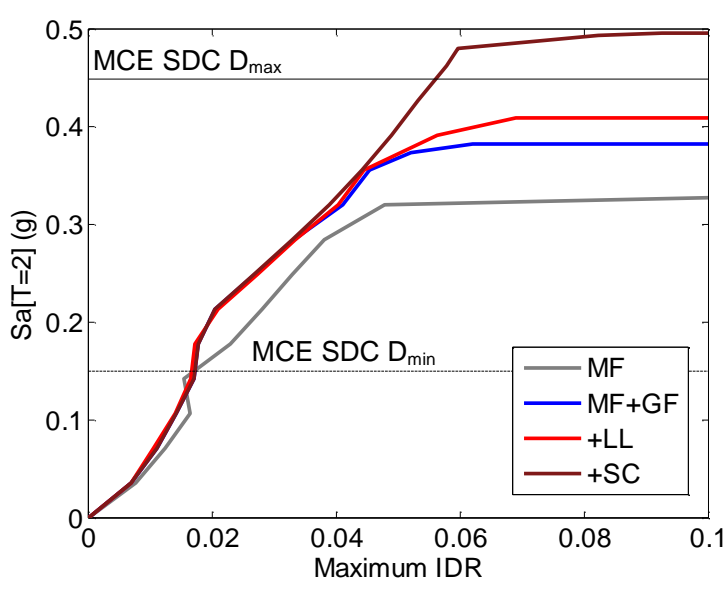

a) LOS000 IDA curves

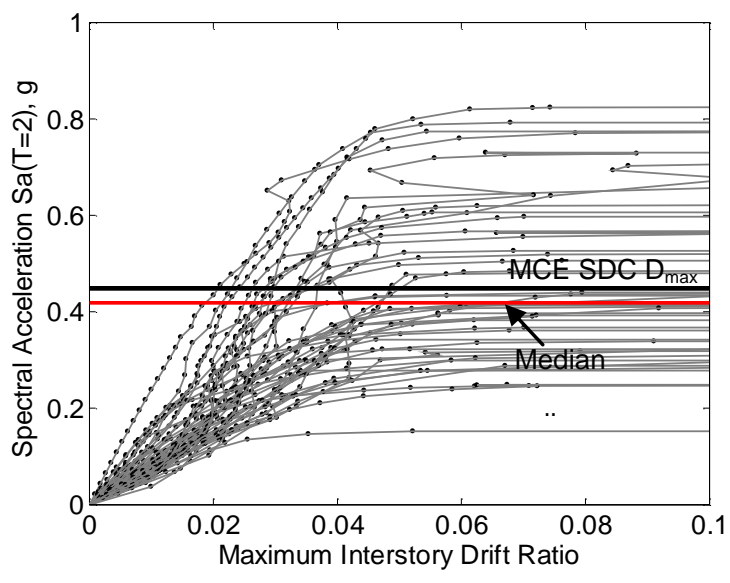

b) IDA curves for MF+GF archetype

Fig. 13. Typical response of 4-story building with non-ductile moment frames.

where epistemic uncertainty was incorporated by assigning dispersion due to design, $\beta_{D R}$ test data, $\beta_{T D}$ and modeling uncertainty, $\beta_{M D L}$. Using the FEMA P-695 rubric, $\beta_{D R}=0.2$ ('Good'), and $\beta_{T D}=\beta_{M D L}=0.35$ ('Fair') was used for non-ductile frame buildings; $\beta_{D R}=0.1$ ('Superior'), and $\beta_{T D}=\beta_{M D L}=0.2$ was used for ductile frame buildings. Fig. $14 \mathrm{~b}$ compares the collapse fragility curves based on the total dispersion in collapse capacity.

The collapse assessment results are summarized in Table 2 and Table 3. It is noted that the fundamental period values determined in the eigenvalue analysis, $T_{1}$ are high compared to empirical estimates of actual buildings. Nevertheless, the periods are similar to those reported in the ATC-76 report. The static pushover results are described in terms of the seismic base shear coefficient $C_{s}$ and static “overstrength" $\Omega$ for SDC $\mathrm{D}_{\max }$, and period-based ductility $\mu_{T}$, described in FEMA P-695. Since the non-ductile moment frames were designed for SDC $\mathrm{B}_{\min }$ the values of $\Omega$ in Table 2 are less than 1.0 (meaning, these buildings are under-strength relative to SDC $\left.D_{\max }\right)$. The dynamic IDA results are shown relative to SDC $\mathrm{D}_{\max }$ and include the intensity 
measure (the spectral acceleration corresponding to the MCE ground motion $S_{a}{ }^{M C E}$ ), collapse margin ratio $(C M R)$, Spectral Shape Factor $(S S F)$, adjusted $C M R(A C M R)$, record-to-record dispersion $\beta_{R T R}$, total dispersion $\beta_{\text {Total }}$, and the probability of collapse conditioned on the MCE level ground motion, $P_{c} \mid M C E$. For brevity, results relative to $S D C \mathrm{D}_{\min }$ are not shown.

The reserve lateral strength in the shear-tab connections reduced the collapse probability considerably compared to moment frames alone. Employing collapse prevention mechanisms improved the collapse safety, but the amount of improvement depended on the number of stories and the collapse inhibiting mechanism. Collapse prevention systems with a non-ductile momentframe passed the FEMA P-695 acceptance criteria for SDC $\mathrm{D}_{\min }$. For collapse prevention systems with ductile moment-frames, the short-period (1-story, 2-story) performance group and the 4-story buildings passed the acceptance criteria for SDC $\mathrm{D}_{\max }$.

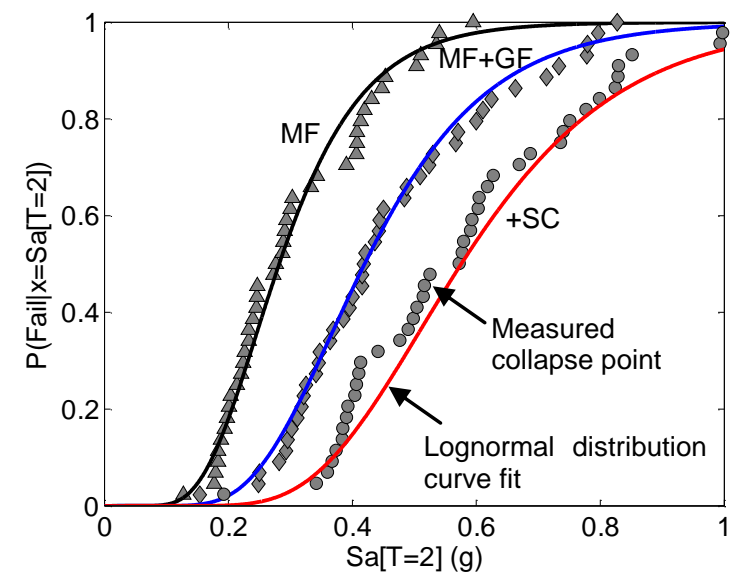

a) Collapse fragility curves

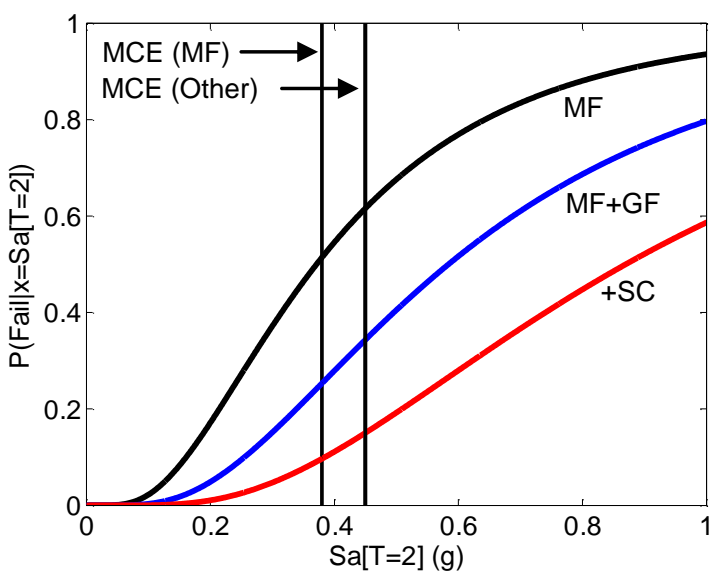

b) Collapse fragility curves with $\beta_{\text {Total }}$

Fig. 14. Results for 4-story building with non-ductile moment frames. 
Table 2. Collapse assessment (for SDC $D_{\max }$ ) for non-ductile moment-frame building (designed for wind, SDC $\left.\mathrm{B}_{\min }\right)$.

\begin{tabular}{|c|c|c|c|c|c|c|c|c|c|c|c|}
\hline \multirow[b]{2}{*}{ Archetype } & \multirow[b]{2}{*}{$\begin{array}{l}\text { T1 } \\
\text { (s) }\end{array}$} & \multicolumn{3}{|c|}{ Static Pushover } & \multicolumn{7}{|c|}{ Dynamic IDA } \\
\hline & & Cs & $\boldsymbol{\Omega}$ & $\mu \mathbf{T}$ & $\begin{array}{c}\text { SaMCE } \\
\text { (g) }\end{array}$ & CMR & SSF & ACMR & $\beta R T R$ & $\beta$ Total & Pc | MCE \\
\hline \multicolumn{12}{|c|}{ 1-Story } \\
\hline MF & 1.52 & 0.33 & 0.41 & 1.16 & 0.59 & 0.81 & 1.10 & 0.90 & 0.38 & 0.65 & $57 \%$ \\
\hline $\mathrm{MF}+\mathrm{GF}$ & 1.14 & 0.33 & 0.66 & 2.72 & 0.79 & 1.11 & 1.25 & 1.39 & 0.38 & 0.65 & $31 \%$ \\
\hline$+\mathrm{SC}$ & 1.13 & 0.33 & 0.75 & 3.13 & 0.80 & 1.30 & 1.28 & 1.66 & 0.37 & 0.65 & $22 \%$ \\
\hline$+\mathrm{LL}$ & 1.14 & 0.33 & 0.75 & 2.42 & 0.79 & 1.25 & 1.23 & 1.54 & 0.34 & 0.64 & $25 \%$ \\
\hline \multicolumn{12}{|c|}{ 2-Story } \\
\hline MF & 1.87 & 0.33 & 0.28 & 1.89 & 0.48 & 0.59 & 1.22 & 0.72 & 0.38 & 0.66 & $69 \%$ \\
\hline $\mathrm{MF}+\mathrm{GF}$ & 1.58 & 0.33 & 0.39 & 1.45 & 0.57 & 0.95 & 1.16 & 1.10 & 0.36 & 0.64 & $44 \%$ \\
\hline$+\mathrm{SC}$ & 1.58 & 0.33 & 0.39 & 3.26 & 0.57 & 1.42 & 1.34 & 1.91 & 0.34 & 0.63 & $15 \%$ \\
\hline$+\mathrm{LL}$ & 1.58 & 0.33 & 0.44 & 3.30 & 0.57 & 1.24 & 1.35 & 1.67 & 0.33 & 0.63 & $21 \%$ \\
\hline \multicolumn{12}{|c|}{ 4-Story } \\
\hline MF & 2.38 & 0.21 & 0.33 & 2.90 & 0.38 & 0.74 & 1.32 & 0.98 & 0.37 & 0.65 & $51 \%$ \\
\hline $\mathrm{MF}+\mathrm{GF}$ & 2.01 & 0.21 & 0.41 & 3.94 & 0.45 & 0.93 & 1.39 & 1.30 & 0.37 & 0.65 & $34 \%$ \\
\hline$+\mathrm{SC}$ & 2.01 & 0.21 & 0.42 & 6.00 & 0.45 & 1.28 & 1.51 & 1.93 & 0.35 & 0.64 & $15 \%$ \\
\hline$+\mathrm{LL}$ & 2.01 & 0.21 & 0.41 & 4.01 & 0.45 & 1.00 & 1.40 & 1.39 & 0.36 & 0.64 & $30 \%$ \\
\hline \multicolumn{12}{|c|}{ 8-Story } \\
\hline MF & 3.16 & 0.12 & 0.43 & 3.26 & 0.28 & 0.65 & 1.34 & 0.87 & 0.44 & 0.69 & $58 \%$ \\
\hline $\mathrm{MF}+\mathrm{GF}$ & 2.85 & 0.12 & 0.55 & 2.35 & 0.32 & 0.87 & 1.27 & 1.10 & 0.34 & 0.63 & $44 \%$ \\
\hline$+\mathrm{SC}$ & 2.86 & 0.12 & 0.56 & 1.99 & 0.32 & 1.03 & 1.23 & 1.27 & 0.36 & 0.64 & $36 \%$ \\
\hline$+\mathrm{LL}$ & 2.85 & 0.12 & 0.55 & 3.11 & 0.32 & 0.75 & 1.33 & 1.0 & 0.50 & 0.73 & $50 \%$ \\
\hline
\end{tabular}


Table 3. Collapse assessment (for SDC $D_{\max }$ ) for ductile moment-frame building (designed for

SDC $\left.D_{\min }\right)$.

\begin{tabular}{|c|c|c|c|c|c|c|c|c|c|c|c|}
\hline \multirow[b]{2}{*}{ Archetype } & \multirow[b]{2}{*}{$\begin{array}{l}\text { T1 } \\
\text { (s) }\end{array}$} & \multicolumn{3}{|c|}{ Static Pushover } & \multicolumn{7}{|c|}{ Dynamic IDA } \\
\hline & & Cs & $\boldsymbol{\Omega}$ & $\mu T$ & $\begin{array}{c}\text { SaMCE } \\
\text { (g) }\end{array}$ & CMR & SSF & ACMR & $\beta R T R$ & $\beta$ Total & Pc | MCE \\
\hline \multicolumn{12}{|c|}{ 1-Story } \\
\hline MF & 1.46 & 0.13 & 1.38 & 2.97 & 0.62 & 1.53 & 1.32 & 2.01 & 0.44 & 0.53 & $9 \%$ \\
\hline $\mathrm{MF}+\mathrm{GF}$ & 1.11 & 0.13 & 2.16 & 3.43 & 0.81 & 1.64 & 1.29 & 2.12 & 0.43 & 0.52 & $7 \%$ \\
\hline$+\mathrm{SC}$ & 1.11 & 0.13 & 2.53 & 2.88 & 0.81 & 1.74 & 1.26 & 2.19 & 0.40 & 0.50 & $6 \%$ \\
\hline$+\mathrm{LL}$ & 1.11 & 0.13 & 2.16 & 3.43 & 0.81 & 1.71 & 1.29 & 2.21 & 0.42 & 0.51 & $7 \%$ \\
\hline \multicolumn{12}{|c|}{ 2-Story } \\
\hline MF & 1.55 & 0.13 & 1.28 & 3.66 & 0.58 & 1.33 & 1.37 & 1.82 & 0.47 & 0.56 & $14 \%$ \\
\hline $\mathrm{MF}+\mathrm{GF}$ & 1.36 & 0.13 & 1.73 & 3.98 & 0.66 & 1.71 & 0.43 & 2.34 & 0.43 & 0.53 & $5 \%$ \\
\hline$+\mathrm{SC}$ & 1.36 & 0.13 & 1.83 & 4.85 & 0.66 & 1.85 & 1.42 & 2.63 & 0.37 & 0.48 & $2 \%$ \\
\hline$+\mathrm{LL}$ & 1.36 & 0.13 & 1.73 & 3.98 & 0.66 & 1.78 & 1.37 & 2.44 & 0.40 & 0.50 & $4 \%$ \\
\hline \multicolumn{12}{|c|}{ 4-Story } \\
\hline MF & 1.75 & 0.08 & 1.48 & 5.06 & 0.51 & 1.17 & 1.46 & 1.71 & 0.34 & 0.46 & $12 \%$ \\
\hline $\mathrm{MF}+\mathrm{GF}$ & 1.60 & 0.08 & 1.80 & 4.92 & 0.56 & 1.45 & 1.45 & 2.11 & 0.32 & 0.44 & $5 \%$ \\
\hline$+\mathrm{SC}$ & 1.60 & 0.08 & 1.80 & 6.19 & 0.56 & 1.63 & 1.52 & 2.48 & 0.36 & 0.47 & $3 \%$ \\
\hline$+\mathrm{LL}$ & 1.60 & 0.08 & 1.79 & 5.19 & 0.56 & 1.48 & 1.47 & 2.17 & 0.34 & 0.45 & $4 \%$ \\
\hline \multicolumn{12}{|c|}{ 8-Story } \\
\hline MF & 3.18 & 0.05 & 1.15 & 3.04 & 0.28 & 0.66 & 1.33 & 0.88 & 0.37 & 0.48 & $61 \%$ \\
\hline $\mathrm{MF}+\mathrm{GF}$ & 2.88 & 0.05 & 1.31 & 3.44 & 0.31 & 0.87 & 1.36 & 1.18 & 0.34 & 0.46 & $36 \%$ \\
\hline$+\mathrm{SC}$ & 2.88 & 0.05 & 1.34 & 3.99 & 0.31 & 1.03 & 1.39 & 1.43 & 0.34 & 0.46 & $22 \%$ \\
\hline$+\mathrm{LL}$ & 2.88 & 0.05 & 1.31 & 3.52 & 0.31 & 0.96 & 1.36 & 1.31 & 0.34 & 0.45 & $27 \%$ \\
\hline
\end{tabular}


A risk analysis was used to illustrate geographic areas where collapse prevention concept is viable. The annual collapse risk (probability of collapse considering the likelihood of seismicity), $\lambda_{F}$ was calculated in Eq. $14[42,43]$ by integrating the collapse fragility curve, $P(F \mid a)$ with parameters $S_{a}{ }^{M C E}, A C M R$ and $\beta_{\text {Total }}$ given in Table 2 and Table 3, and the seismic hazard data, $\lambda_{a}$ from the 2008 USGS National Seismic Hazard Map data.

$$
\lambda_{F}=-\int_{0}^{+\infty} P(F \mid a)\left(\frac{d \lambda_{a}}{d a}\right) d a
$$

The seismic hazard data was adjusted for site amplification (corresponding to site class D used in the FEMA P-695 evaluation) based on a correlation between shear wave velocity, $V_{s 30}$, and bedrock motion using Next Generation Attenuation (NGA) relationships [44]. This process was repeated for every 0.5 -degree latitude and longitude and the risk of collapse, $P_{F}$ during the lifetime of the building, $t_{\text {exposure }}$ (typically taken as 50 years) was calculated using Eq. 15.

$$
P_{F}=1-e^{-\lambda_{F} t_{\text {exposure }}}
$$

Fig. 15 shows regions (indicated by contour lines) where collapse risk in 50 years exceeds the code target of $1 \%$. Light blue and purple shaded areas in the central and eastern United States indicate regions where the collapse prevention system using slack cables is beneficial (i.e. it is limiting the collapse risk to less than $1 \%$ in 50 years). Red shaded areas indicate where the collapse prevention system is not sufficient (collapse risk is greater than $1 \%$ in 50 years). The figure shows that the slack cable collapse prevention system provided a $1 \%$ or less risk of collapse in many areas of the central and eastern United States, but the applicability depended on the number of stories. The region covered by the slack cable collapse prevention system is the blue and purple shaded areas, and represents a significant portion of the United States population. 


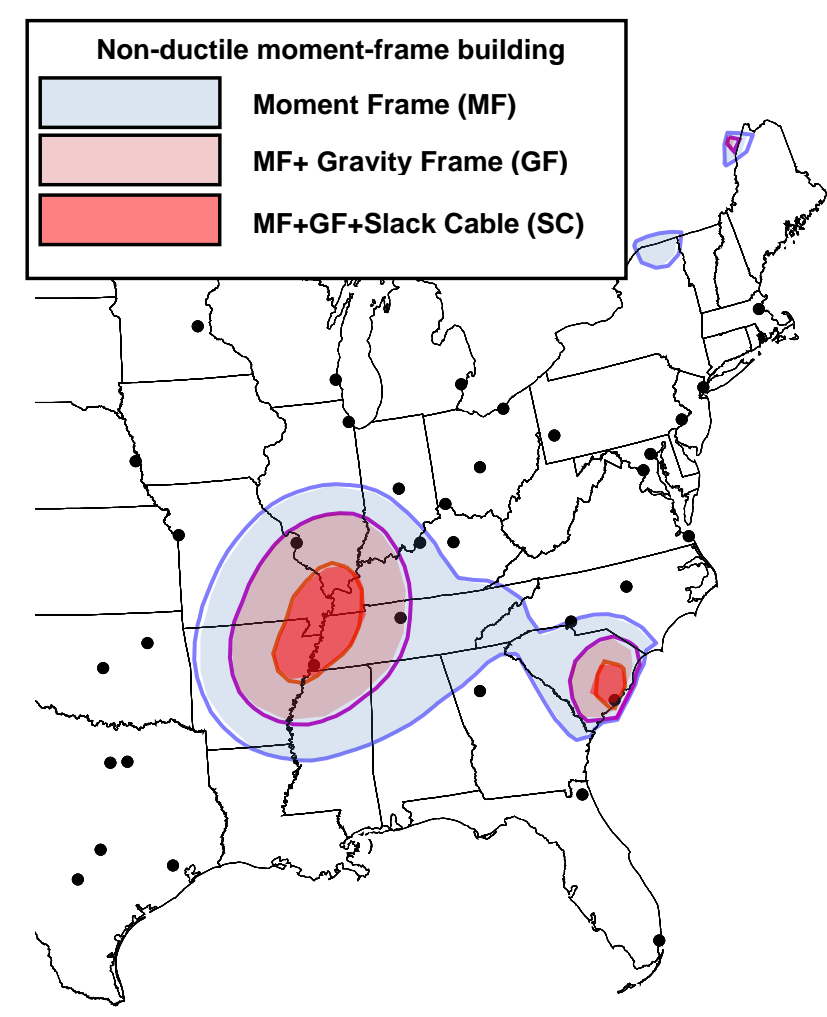

a) 2-story building

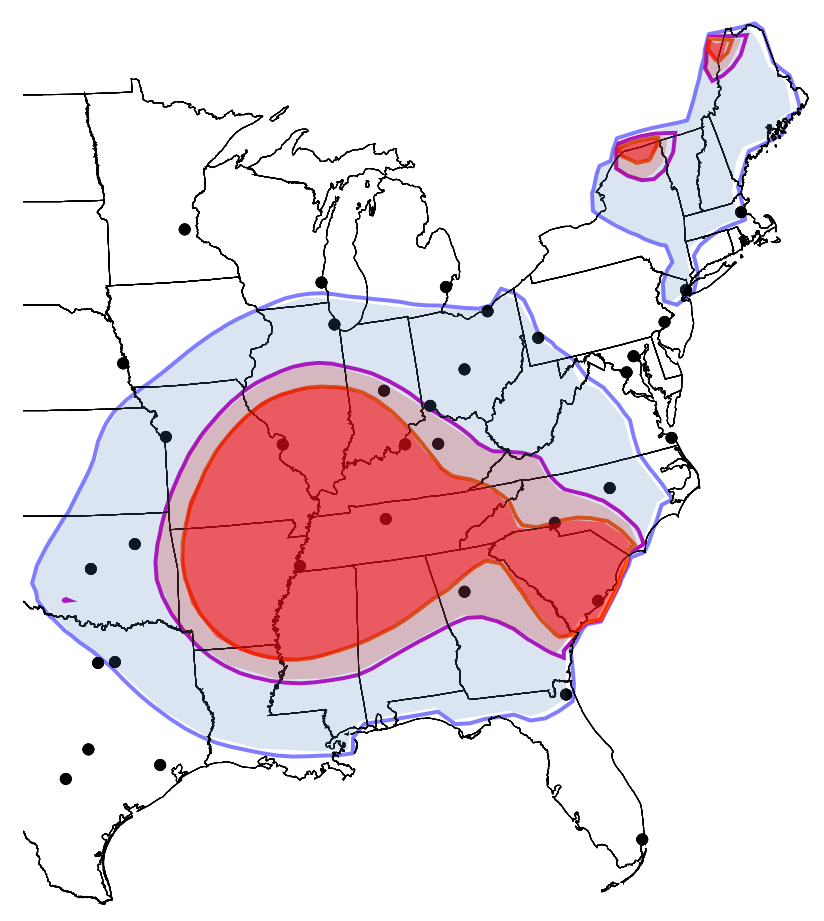

b) 8 -story building

Fig. 15. Regions where collapse risk exceeds $1 \%$ in 50 years.

\section{Serviceability Performance Assessment}

The improved performance for serviceability of non-ductile moment-frame buildings with collapse prevention systems augmented with energy dissipation devices was assessed using the FEMA P-58 framework [45,46] and companion software, PACT [47]. This assessment was accomplished in a two-tier process. First, the structural response for a given hazard intensity level was determined (using the same analytical models used for the collapse assessment). Second, the sensitivity of structural components, non-structural components, and other critical 
components of the building to ground shaking was determined using PACT and the structural response results. A similar evaluation at other intensity levels was performed in a related study [48].

A sub-set of 7 ground motion component pairs was selected from the FEMA P-695 FarField Suite and scaled to $10 \%$ of the spectral acceleration corresponding to the MCE. As previously discussed, this intensity level corresponds to a 72-year MRI for the central and eastern United States.

Table 4 summarizes the component fragilities used in the assessment. The component fragilities used in the assessment were determined using the FEMA P-58 Normative Quantity Estimation Tool. Structural components consisted of beam-to-column connections, column splices, and base plates. Although components of the collapse-inhibiting mechanism, such as cables, links, and HSS members could not be included (since the fragility test data was not yet available) it is likely that the ease of access and size would mitigate (lower) costs, compared to other components. Non-structural components included a variety of items, ranging from mechanical, electrical, and plumbing (MEP) to exterior cladding and partition walls. Earthquake ground shaking intensity was correlated to component performance by median demand, $\theta$ and dispersion, $\beta$ parameters. Structural components used interstory drift ratio (IDR). Nonstructural components used floor or roof acceleration. All IDR parameters were directional, meaning that the performance depended on the building direction, and all accelerations are nondirectional. Quantities of components were estimated using the FEMA P-58 spreadsheet tools [49] and depended on the number of stories and the component type. For example, buildings with the moment frame columns not fixed at the base (1-story and 2-story buildings) did not utilize the base plate fragility. 
Table 4. Summary of component fragilities.

$\left(1 \mathrm{lf}=0.31 \mathrm{~m}, 1 \mathrm{sf}=0.09 \mathrm{~m}^{2}, 1 \mathrm{cf}=0.03 \mathrm{~m}^{3}\right.$, and $\left.1 \mathrm{tn}=8.9 \mathrm{kN}\right)$

\begin{tabular}{|c|c|c|c|}
\hline \multicolumn{2}{|c|}{ Component Description (FEMA P-58 Fragility ID) } & Quantity & $\begin{array}{l}\text { Demand } \\
\text { Parameter }\end{array}$ \\
\hline \multicolumn{4}{|c|}{ Structural Components } \\
\hline \multirow{3}{*}{ Beam-to-column connections } & Non-ductile, Pre-Northridge WUF-B, single sided (B1035.041) & 4 & IDR \\
\hline & 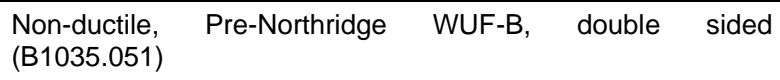 & 4 & IDR \\
\hline & Gravity frame, bolted shear tab (B1031.001) & 32 & IDR \\
\hline \multirow{2}{*}{ Moment frame columns } & Base plates with column $\mathrm{W}<150$ plf (B1031.011a) & 8 & IDR \\
\hline & Column $\mathrm{W}<150$ plf (B1031.021a) & 8 & IDR \\
\hline \multicolumn{4}{|c|}{ Non-Structural Components } \\
\hline \multirow{15}{*}{ All stories } & Curtain Walls (B2022.001) & $4,200 \mathrm{sf}$ & IDR \\
\hline & Wall Partition (C1011.001a) & 1,400 If & IDR \\
\hline & Prefabricated steel stair (C2011.001b) & 2 ea & IDR \\
\hline & Wall Partition (C3011.001a) & 106 If & IDR \\
\hline & Raised Access Floor (C3027.001) & $10,500 \mathrm{sf}$ & Acceleration \\
\hline & Suspended Ceiling (C3032.001a) & $12,600 \mathrm{sf}$ & Acceleration \\
\hline & Independent Pendant Lighting (C3034.001) & 210 ea & Acceleration \\
\hline & Cold Water Piping (D2021.011a) & 210 If & Acceleration \\
\hline & HVAC Metal Ducting (D3041.011a) & 1,050 If & Acceleration \\
\hline & HVAC Metal Ducting (D3041.012a) & 280 If & Acceleration \\
\hline & HVAC Drops (D3041.031a) & 126 ea & Acceleration \\
\hline & (VAV) box (D3041.041a) & 98 ea & Acceleration \\
\hline & Fire Sprinkler Water Piping (D4011.021a) & 2,800 If & Acceleration \\
\hline & Fire Sprinkler Drop (D4011.031a) & 126 ea & Acceleration \\
\hline & Low Voltage Switchgear (D5012.021a) & 225 ea & Acceleration \\
\hline 1st story & Traction Elevator (D1014.011) & 4 ea & Acceleration \\
\hline \multirow{4}{*}{ Roof } & Chiller (D3031.011a) & $360 \mathrm{tn} / \mathrm{ea}$ & Acceleration \\
\hline & Cooling Tower (D3031.021a) & $360 \mathrm{tn} / \mathrm{ea}$ & Acceleration \\
\hline & Air Handling Unit (D3052.011a) & $88,200 \mathrm{cf}$ & Acceleration \\
\hline & Motor Control Center (D5012.013a) & 6 ea & Acceleration \\
\hline
\end{tabular}


Fig. 16 shows median peak interstory drift ratio (IDR) and accelerations. The collapse prevention system using loose-linkages with dampers limited drift below the threshold limit for visual damage under wind loads (0.003) [50]. Accelerations exceed the threshold for human comfort $(0.025 \mathrm{~g})$ at high-frequency motion in an office building $[50,51,52]$, although this is probably not an issue for the short duration of shaking.

The sensitivity to ground motion for two selected components is shown in Fig. 17. In FEMA P-58 sensitivity is described in terms of "damage" consequences. There are three damage states and associated consequences for wall partitions, but only one damage state for chillers. Based on comparing the fragility curves with the median peak interstory drift ratio and acceleration response, the collapse prevention system using loose-linkages with dampers eliminated moderate and significant damage to wall partitions. Damage to shear-tab connections is unlikely to be important at this intensity level, but serious damage to the chiller is possible. For reference, exterior cladding damage fragility (not shown) has a median demand, $\theta=0.04$ interstory drift ratio and dispersion, $\beta=0.4$. Thus, no damage to glazing is expected.

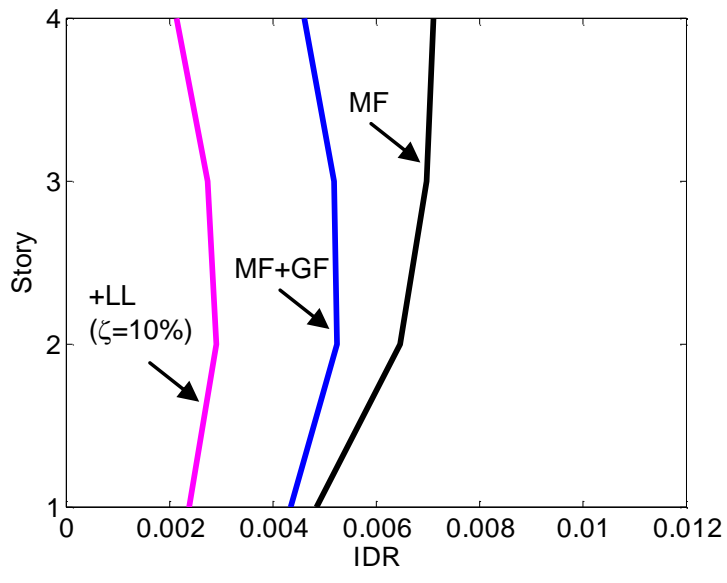

a) Median inter-story drift ratio (IDR)

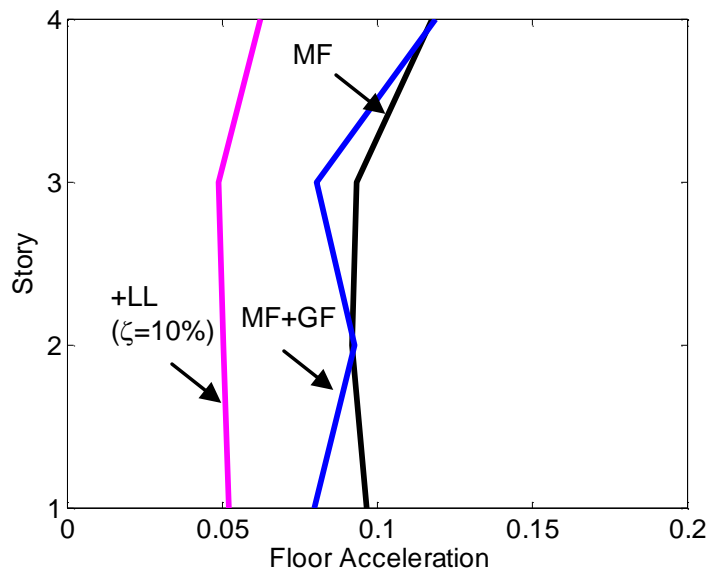

b) Median peak floor acceleration

Fig. 16. Response for 4-story non-ductile moment-frame building at 10\% of MCE. 


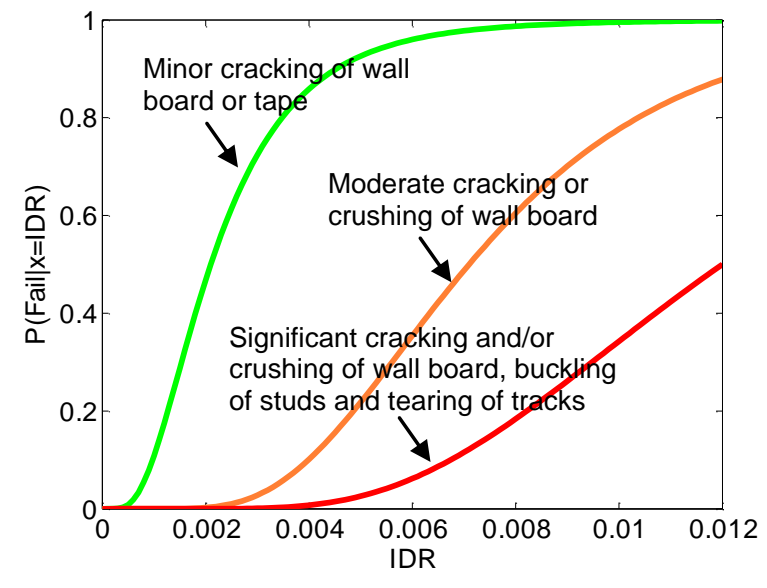

a) Wall partition fragilities

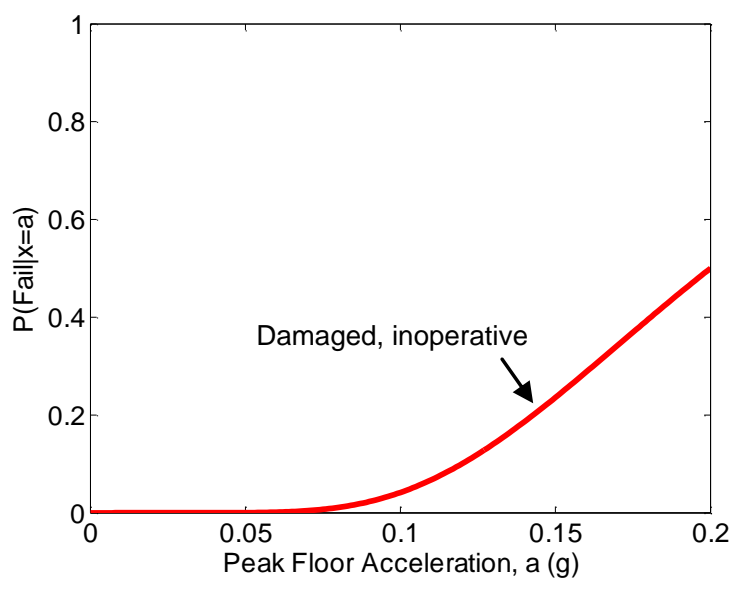

b) Chiller fragility

Fig. 17. Selected component fragilities (sensitivity to ground motion).

Comprehensive building performance was predicted in PACT using Monte Carlo simulations using the results from the structural analysis (interstory drift ratio and floor/roof accelerations) and the median demand values and dispersion for all component fragilities and associated damage consequences.

Table 5 provides the median repair cost, $C_{\text {Repair }}$ and time, $t_{\text {Repair }}$, and the probability of unsafe placards determined in the PACT analyses. Resilience, $R$ is calculated using Eq. 16 originally proposed by Bruneau and Reinhorn [53] for a reference time, $t_{c}$ of 60 days.

$$
\begin{aligned}
R & =\int_{t_{0}}^{t_{c}}[1-Q(t)] d t \\
& =1-\frac{1}{2}\left(\frac{C_{\text {Repair }}+P_{\text {Placard }} C_{\text {Tenant }}}{C_{\text {Total }}}\right)\left(\frac{t_{\text {Repair }}}{t_{c}}\right)
\end{aligned}
$$


Table 5. Serviceability performance of the non-ductile moment-frame buildings.

\begin{tabular}{|c|c|c|c|c|}
\hline \multirow{2}{*}{$\begin{array}{l}\text { Archetype } \\
\text { Model }\end{array}$} & \multicolumn{2}{|c|}{ Repair } & \multirow{2}{*}{$\begin{array}{l}\text { Prob. of } \\
\text { Unsafe } \\
\text { Placards }\end{array}$} & \multirow{2}{*}{$\begin{array}{c}\text { Resilience } \\
\boldsymbol{R}\end{array}$} \\
\hline & Cost (\$) & Time (days) & & \\
\hline \multicolumn{5}{|c|}{ 1-story } \\
\hline MF & 277,500 & 50 & 0.49 & 0.82 \\
\hline $\mathrm{MF}+\mathrm{GF}$ & 220,000 & 32 & 0.26 & 0.93 \\
\hline$+\mathrm{LL}(\zeta=10 \%)$ & 108,500 & 19 & 0.10 & 0.98 \\
\hline$+\mathrm{TB}(\zeta=10 \%)$ & 115,000 & 20 & 0.10 & 0.98 \\
\hline \multicolumn{5}{|c|}{ 2-story } \\
\hline MF & 330,000 & 36 & 0.21 & 0.94 \\
\hline $\mathrm{MF}+\mathrm{GF}$ & 266,250 & 32 & 0.15 & 0.96 \\
\hline$+\mathrm{LL}(\zeta=10 \%)$ & 181,250 & 23 & 0.05 & 0.99 \\
\hline$+\mathrm{TB}(\zeta=10 \%)$ & 172,000 & 23 & 0.05 & 0.99 \\
\hline \multicolumn{5}{|c|}{ 4-story } \\
\hline MF & 666,667 & 40 & 0.19 & 0.94 \\
\hline $\mathrm{MF}+\mathrm{GF}$ & 490,000 & 27 & 0.09 & 0.98 \\
\hline$+\mathrm{LL}(\zeta=10 \%)$ & 211,000 & 14 & 0.01 & 1.00 \\
\hline$+\mathrm{TB}(\zeta=10 \%)$ & 196,875 & 14 & 0.01 & 1.00 \\
\hline \multicolumn{5}{|c|}{ 8-story } \\
\hline MF & $1,192,000$ & 48 & 0.10 & 0.95 \\
\hline $\mathrm{MF}+\mathrm{GF}$ & 775,000 & 29 & 0.03 & 0.99 \\
\hline$+\mathrm{LL}(\zeta=10 \%)$ & 458,333 & 18 & 0.01 & 1.00 \\
\hline$+\mathrm{TB}(\zeta=10 \%)$ & 445,000 & 18 & 0.01 & 1.00 \\
\hline
\end{tabular}

The total replacement cost, $C_{\text {Total }}$ of a moment-frame building has been suggested in the literature $[54,55,56]$ to be anywhere from 150 to 350 dollars/sf, where the upper end of cost was representative of construction on the west coast. In this study the focus was on steel-framed buildings constructed in a low or moderate seismic area in the central and eastern United States, so the total replacement cost for the prototype building was estimated at 230 dollars/sf with $30 \%$ attributed to the core and shell (building cost excluding tenant improvements, $C_{\text {Tenant }}$ ).

The lateral strength in shear tab connections and the collapse prevention system with energy dissipation devices contributed to a significant reduction in both repair cost and 
downtime. The improvement was most dramatic in the 1-story building. For the 1-story, 2story, and 4-story buildings, the probability of an unsafe placard ("red tag") for the conventional building (MF only) is primarily due to the probability of structural damage to the non-ductile moment frame connections. Collapse prevention systems were highly resilient compared to the conventional building.

\section{Comparative Cost}

The competitiveness of a collapse prevention system for new construction was evaluated for the 4-story non-ductile building design. More than $80 \%$ of the cost of constructing a new steel building may be attributed to material costs, fabrication labor costs, and erection labor costs [57]. To estimate the material costs, moment-frame beam and column sizes were compared to sizes used for a ductile SMF moment frame building design [26]. Based on this comparison, the nonductile moment frame requires up to $37 \%$ to $47 \%$ less steel than a ductile moment frame, depending on the seismic design category of the location. The collapse prevention system would have the additional material cost for cables, links, braces, or energy dissipation devices, depending on the collapse inhibiting mechanism installed, but these costs are comparatively smaller. Importantly, the collapse inhibiting mechanisms do not add initial stiffness to the building. A stiffer structural frame "collects" force and tends to increase the foundation size and connection materials required to transfer these forces.

The labor required to assemble and inspect ductile moment connections typically drives up the cost, in comparison to non-ductile moment-frame systems and braced-frame systems that are not specifically detailed for seismic resistance [58]. This suggests that, considering only the frame, labor costs would be comparatively lower for the collapse prevention systems using non- 
ductile moment frames. Installing slack cables would likely incur relatively small installation costs. Installing loose-linkages, however, may offset labor savings from the frame due to column and beam stiffeners at the linkage attachment, and other detailing. Of course, energy dissipation devices (if used) would add to the total cost of the system.

The remaining construction costs include special inspections and other additional costs, such as scheduling constraints. Since collapse prevention systems using non-ductile moment frames would not have demand-critical field welding, fewer and less difficult special inspections are expected, compared to welded ductile moment frames.

\section{Conclusions}

In many locations of the United States, the only seismic limit state of consequence is life safety. The collapse prevention system may provide a cost-effective solution for these locations. The collapse prevention system concept relies on components that, working together with the primary lateral force-resisting system and gravity framing, are specifically designed to prevent collapse.

Reserve lateral strength provided by the shear tab beam-to-column connections was a significant factor in the success of the collapse prevention system. In most buildings the reserve strength significantly reduced the probability of collapse for the MCE level ground motion. Collapse prevention systems using non-ductile moment frames with fully-restrained directly welded flange connections passed the FEMA P-695 criteria for SDC $\mathrm{D}_{\min }$. Collapse prevention systems were adequate for many regions in the central and eastern United States, but a conventional system or a collapse prevention system with a ductile moment frame would be required for regions of higher seismicity (e.g. New Madrid and Charleston areas). 
The investigation of collapse prevention systems leads to two general recommendations for performance-based analysis and design in earthquake engineering. The first recommendation is that gravity framing should be included in structural analysis. The inherent added stiffness and strength have profound effects on collapse capacity behavior. By implication, the effect of the gravity framing on the response also leads to the recommendation that three-dimensional modeling, including torsional effects, may be needed to better understand collapse behavior.

The study leads to two specific recommendations for the collapse prevention system concept. First, collapse prevention systems need to be optimized. In this study, the strength of the collapse prevention systems was limited by the size of the gravity frame members, and future research should investigate collapse prevention systems with slightly larger gravity framing members (especially column sizes). This study also revealed that ductility may have a larger impact than strength on the collapse capacity of the collapse prevention system. Accordingly, it may be advantageous to utilize inherent ductility, such as panel zone yielding. Collapse prevention systems with distributed forms of damping (such as friction dampers) could also be investigated.

Second, the collapse prevention system concept is equally relevant (and perhaps more attractive) for the repair and retrofit of existing buildings. While the previous recommendations relate to the use of collapse prevention systems in new construction, an important advantage in using collapse prevention systems for rehabilitation (compared to a traditional retrofit) is that the collapse prevention mechanism need not be part of the main lateral load resisting system. A related advantage is that the collapse prevention system concept has less reliance on added deformation capacity, which is a key factor in older construction. For that reason, collapse prevention systems could likewise be used to prevent collapse of a damaged building during a 
strong aftershock. Moreover, it is likely that current retrofit methodologies as outlined in ASCE 41-13 will not be applicable to buildings with collapse prevention systems arising from differences between western United States and central and eastern United States seismicity, and due to the concept that the main lateral force-resisting system and gravity framing is expected to provide adequate performance at all limit states except life-safety and collapse. This situation would need to be assessed before implementation of the collapse prevention system concept.

\section{Acknowledgements}

This research was supported by the National Institute of Standards and Technology (NIST) grant No. 60ANB10D107 and The Charles E. Via, Jr. Department of Civil and Environmental Engineering at Virginia Tech. The opinions, findings, and conclusions presented in this paper are those of the authors and do not necessarily reflect the views of the organizations acknowledged.

\section{References}

[1] ASCE. Minimum design loads for buildings and other structures (ASCE/SEI 7-10). American Society of Civil Engineers, Reston, Virginia; 2010.

[2] ICC (2012). International Performance Code. International Code Council, Inc. Publications, Country Club Hills, Illinois.

[3] Seligson HA, Eguchi RT. The true cost of earthquake disasters: an updated tabulation of losses for the 1994 Northridge earthquake. International Symposium on Earthquake Engineering, Kobe, Japan; 2005. 
[4] Hamburger RO, Rojahn C, Heintz JA, Mahoney MG. FEMA P58: Next-generation building seismic performance assessment methodology. 15th World Conference on Earthquake Engineering, Lisbon, Portugal; 2012.

[5] Judd JP, Charney FA. Performance-based design in the central and eastern United States. Structures Congress, Boston, Massachusetts; 2014.

[6] USGS (2010). 2009 Earthquake Probability Mapping. United States Geological Survey United States, http://geohazards.usgs.gov/eqprob/2009/.

[7] Judd JP, Charney FA. Seismic performance of buildings designed for wind. Structures Congress, Boston, Massachusetts; 2014.

[8] Liu J, Astaneh-Asl A. Cyclic testing of simple connections including effects of slab. Journal of Structural Engineering 2000; 126(1): 32-39.

[9] Liu J, Astaneh-Asl A. Moment-rotation parameters for composite shear tab connections. Journal of Structural Engineering 2004; 130(9): 1371-1380.

[10] Fahnestock, L. A. Collapse resistance of low ductility braced frames. Quake Summit 2012 for the George E. Brown, Jr. Network for Earthquake Engineering Simulation (NEES) program of the National Science Foundation (NSF), July 9 - 12, Boston, Massachusetts; 2012.

[11] Ariyaratana, C., and Fahnestock, L. A. Evaluation of buckling-restrained braced frame seismic performance considering reserve strength. Engineering Structures 2011; 33: 77-89.

[12] Eatherton MR, Hajjar JF. Residual drifts of self-centering systems including effects of ambient building resistance. Earthquake Spectra 2011; 27(3): 719-744. 
[13] Flores FX, Charney FA, Lopez-Garcia D. Influence of the gravity framing system on the collapse performance of special steel moment frames. Journal of Construction Steel Research 2014; 101:351-362.

[14] Judd JP, Charney FA. Seismic performance of buildings designed for wind. Structures Congress, Boston, Massachusetts; 2014.

[15] NIST. Applicability of nonlinear multiple-degree-of-freedom modeling for design: supporting documentation. Report No. GRC 10-917-9, National Institute of Standards and Technology, Gaithersburg, Maryland; 2010.

[16] Leon RT. Composite connections. Progress in Structural Engineering and Materials 1998; 1(2): 159-169.

[17] Hines, E. M., and Fahnestock, L. A. Design philosophy for steel structures in moderate seismic regions. Proceedings, 9th US National and 10th Canadian Conference on Earthquake Engineering, Toronto, Canada; 2010.

[18] Hines, E. M., Appel, M. E., and Cheever, P. J. Collapse performance of low-ductility chevron braced steel frames in moderate seismic regions. Engineering Journal 2009; Q3: $149-180$.

[19] Nelson, T. A., Gryniuk, M. C., Hines, E. M. Comparison of low-ductility moment resisting frames with chevron braced frames under moderate seismic demands. Proceedings, 8th U.S. National Conference on Earthquake Engineering, April 18-22, San Francisco, California; 2066.

[20] Atlayan O, Charney FA. Lightly damped moment-resisting steel frames: a design-based approach. Engineering Journal 2011; 48(3): 183-197. 
[21] Constantinou MC, Tsopelas P, Hammel W, Sigaher AN. Toggle-brace-damper seismic energy dissipation systems. Journal of Structural Engineering 2001; 127(2): 105-112.

[22] Marshall JD, Charney FA. A hybrid passive control device for steel structures I: Development and analysis. Journal of Constructional Steel Research 2010; 66(10): 12781286.

[23] Marshall JD, Charney FA. A hybrid passive control device for steel structures II: Physical testing. Journal of Constructional Steel Research 2010; 66(10): 1287-1294.

[24] Marshall JD, Charney FA. Seismic response of steel frame structures with hybrid passive control systems. Earthquake Engineering and Structural Dynamics 2012; 41(4): 715-733.

[25] FEMA. Quantification of building seismic performance factors (FEMA P-695). Federal Emergency Management Agency, Washington, D.C.; 2009.

[26] NIST. Evaluation of the FEMA P-695 methodology for quantification of building seismic performance factors. Report No. GRC 10-917-8, National Institute of Standards and Technology, Gaithersburg, Maryland; 2010.

[27] Hamburger, Ronald O., Krawinkler, Helmut, Malley, James O., and Adan, Scott M. Seismic design of steel special moment frames: a guide for practicing engineers. NEHRP Seismic Design Technical Brief No. 2 (NIST Report No. GCR 09-917-3), produced by the NEHRP Consultants Joint Venture, for the National Institute of Standards and Technology, Gaithersburg, Maryland; 2009.

[28] Bruneau, M., Uang, C.-M., and Sabelli, R. Ductile design of steel structures, second edition. The McGraw-Hill Companies, Inc., New York, New York; 2011. 
[29] PEER. Open Systems for Earthquake Engineering Simulation (OpenSees), version 2.4.0. Pacific Earthquake Engineering Research Center, University of California, Berkeley, California; 2012.

[30] Lignos DG, Krawinkler H. Deterioration modeling of steel components in support of collapse prediction of steel moment frames under earthquake loading. Journal of Structural Engineering 2011: 137 (11): 1291-1302.

[31] FEMA. Effects of strength and stiffness degradation on seismic response (FEMA P-440A). Federal Emergency Management Agency, Washington, D.C.; 2009.

[32] ASCE. Seismic evaluation and retrofit of existing buildings (ASCE 41-13). American Society of Civil Engineers, Reston, Virginia; 2014.

[33] FEMA. State of the art report on connection performance (FEMA-355D). Federal Emergency Management Agency, Washington, D.C., 2000.

[34] Elkady A, Lignos DG. Effect of composite action on the dynamic stability of special steel moment resisting frames designed in seismic regions. Structures Congress, Pittsburgh, Pennsylvania; 2014.

[35] Elkady A, Lignos DG. Modeling of the composite action in fully restrained beam-tocolumn connections: implications in the seismic design and collapse capacity of steel special moment frames. Earthquake Engineering \& Structural Dynamics 2014; 43(13): $1935-1954$.

[36] Liu J, Astaneh-Asl A. Cyclic testing of simple connections including effects of slab. Journal of Structural Engineering 2000; 126(1): 32-39.

[37] Liu J, Astaneh-Asl A. Moment-rotation parameters for composite shear tab connections. Journal of Structural Engineering 2004; 130(9): 1371-1380. 
[38] Wen R, Akbas B, Shen J. Practical moment-rotation relations of steel shear tab connections. Journal of Constructional Steel Research 2013; 88: 296-308.

[39] Lowes, L. N., Mitra, N., and Altoonash, A. A beam-column joint model for simulating the earthquake response of reinforced concrete frames. PEER Report 2003/10, Pacific Earthquake Engineering Research Center, University of California, Berkeley, California; 2004.

[40] AISC. Specification for structural steel buildings (AISC 360-10). American Institute of Steel Construction, Chicago, Illinois, 2010.

[41] Charney, F.A., and Marshall, J.D. A comparison of the Krawinkler and scissors models for including beam-column joint deformations in the analysis of steel frames. Engineering Journal 2006; Q1: 31-48.

[42] Kennedy RP. Performance-goal based (risk informed) approach for establishing the SSE site specific response spectrum for future nuclear power plants. Nuclear Engineering and Design 2011; 241: 648-656.

[43] Judd JP, Charney FA. Earthquake risk analysis of structures. 9th International Conference on Structural Dynamics (Eurodyn), Porto, Portugal; 2014.

[44] Huang Y-N, Whittaker AS, Luco N. NEHRP site amplification factors and the NGA relationships. Earthquake Spectra 2010; 26(2): 583-593.

[45] FEMA. Seismic performance assessment of buildings, volume 1-methodology (FEMA P58-1). Federal Emergency Management Agency, Washington, D.C.; 2012.

[46] FEMA. Seismic performance assessment of buildings, volume 2 -implementation guide (FEMA P-58-2). Federal Emergency Management Agency, Washington, D.C.; 2012. 
[47] FEMA. Seismic performance assessment of buildings, volume 3-Performance Assessment Calculation Tool (PACT), version 2.9.65. Federal Emergency Management Agency, Washington, D.C.; 2012.

[48] Jarrett JA, Judd JP, Charney FA. Comparative evaluation of innovative and traditional seismic-resistant systems using FEMA P-58. Journal of Constructional Steel Research 2015; 105: 107-118.

[49] FEMA. Seismic performance assessment of buildings, volume 3-spreadsheet tools. Federal Emergency Management Agency, Washington, D.C.; 2012.

[50] Griffis L. Serviceability limit states under wind. Engineering Journal 1993; 30: 1-16.

[51] Murray TM, Allen DE, Ungar EE. Floor vibrations due to human activity. AISC Design Guide No. 11, 2nd printing. American Institute for Steel Construction, Chicago, Illinois; 2003.

[52] Griffis L, Patel V, Muthukumar S, Baldava S. A framework for performance-based wind engineering. Advances in Hurricane Engineering, ATC and SEI, Miami, Florida; 2012.

[53] Bruneau, M., and Reinhorn, A. Exploring the concept of seismic resilience for acute care facilities. Earthquake Spectra 2007; 23(1): 41-62.

[54] RSMeans. Light commercial cost data. Reed Construction Data, Norwell, Massachusetts; 2011.

[55] ENR. Square foot costbook. Engineering News Record, Design and Construction Resources, Vista, California; 2011.

[56] Zareian, F. PACT Beta Test Example: building A steel special moment frame building. FEMA P-58/BD-3.7.14 Background Document, Federal Emergency Management Agency, Washington, D.C; 2012. 
[57] Carter, C. J., Murray, T. M., and Thornton, W. A. Cost-effective steel building design. Progress in Structural Engineering and Materials 2000; 2(1): 16-25.

[58] Batt, D.P., and Odeh, D.J. A discussion and analysis of ductile detailing requirements for seismic design in moderate seismic regions. Proceedings, Structures Congress, New York; 2005. 